\title{
The impact of shelf tags with Nutri-Score on consumer purchases: a difference-in- difference analysis of a natural experiment in supermarkets of a major retailer in Belgium
}

\author{
Stefanie Vandevijvere ${ }^{*}[$ and Nicolas Berger
}

\begin{abstract}
Background: Delhaize, a major Belgian retailer, started implementing electronic shelf labels (ESL) with Nutri-Score since May 2019. Nutri-Score rates the healthfulness of packaged foods with five colours/letters from red/E (least healthy) to green/A (most healthy). This study evaluated the impact of ESL on consumer purchases, overall, and by food category.

Methods: For 43 intervention stores (implementing ESL in the period 27 May 2019-19 June 2019), a control store, from the same province and retailer-assigned cluster was matched. There were 14 unique control stores. By store, weekly non-food and food sales for 2018 and 2019 were received by Nutri-Score (A/B/C/D/E) and food category according to a retailer-assigned classification system. The primary outcomes were the proportion of food sales for Nutri-Score $A, B, C, D, E$. Difference-in-differences regression analysis was conducted to estimate the effect of the ESL intervention on proportion of overall food and food category sales for Nutri-Score $A, B, C, D, E$, using linear mixed models to account for clustering at store-level. We controlled for store characteristics (region, cluster, non-food sales) and week of the year. Analyses were weighted to re-balance discrepancy between the number of intervention and control stores. To account for multiple testing, a Bonferroni adjustment was applied.

Results: Comparing pre- and post-intervention periods, difference-in-differences for the proportion of NutriScore $B$ and $C$ product sales were more favourable in intervention than control stores $(0.11 \pm 0.04 \%, p=0.007$ and $-0.06 \pm 0.03 \%, p=0.026$ respectively), while difference-in-differences for the proportion of Nutri-Score D product sales were less favourable in intervention than control stores $(0.12 \pm 0.04 \%, p=0.002)$. For $17 / 58$ food categories (representing 29\% of total food sales) a positive impact [increase in healthier (Nutri-Score A, B) and/or decrease in less healthy (Nutri-Score D, E) food sales], and for 16/58 categories (representing $24 \%$ of total food sales) a negative impact was found. Positive impacts were found for vegetable, fruit and dairy products and confectionery. Negative impacts were found for bread and bakery products.
\end{abstract}

Conclusion: The impact of ESL on consumer purchases was mixed. Favourable difference-in-differences were found for Nutri-Score B and C products and unfavourable difference-in-differences for Nutri-Score D products. Shelf labeling on its own is unlikely to significantly influence consumer behaviours.

Keywords: Front-of-pack labeling, Electronic shelf labeling, Nutri-score, Supermarkets, Belgium

*Correspondence: Stefanie.vandevijvere@sciensano.be

Sciensano, Service Lifestyle \& Chronic Diseases, J.Wytsmanstraat 14,

1050 Brussels, Belgium

(C) The Author(s) 2021. Open Access This article is licensed under a Creative Commons Attribution 4.0 International License, which permits use, sharing, adaptation, distribution and reproduction in any medium or format, as long as you give appropriate credit to the original author(s) and the source, provide a link to the Creative Commons licence, and indicate if changes were made. The images or other third party material in this article are included in the article's Creative Commons licence, unless indicated otherwise in a credit line to the material. If material is not included in the article's Creative Commons licence and your intended use is not permitted by statutory regulation or exceeds the permitted use, you will need to obtain permission directly from the copyright holder. To view a copy of this licence, visit http://creativecommons.org/licenses/by/4.0/. The Creative Commons Public Domain Dedication waiver (http://creativeco mmons.org/publicdomain/zero/1.0/) applies to the data made available in this article, unless otherwise stated in a credit line to the data. 


\section{Introduction}

Front-of-pack nutrition (FOP) labelling has been repeatedly recommended by the World Health Organization (WHO) as one of a suite of measures needed to improve population diets $[1,2]$. The policy objectives of FOP labelling are generally twofold: (i) to provide interpretive information to consumers to inform healthier food choices; and (ii) to encourage the food industry to reformulate their products towards healthier options.

Nutri-Score on food packages was first implemented in France in October 2017, and then approved for implementation by the Minister of Public Health in Belgium in August 2018 and has been officially implemented in Belgium since April 1st 2019. The implementation of Nutri-Score on food packages is voluntary. All five biggest food retailers and a few food manufacturers have since either started or committed to put Nutri-Score on the food packages for their own brand products. At the end of 2019 about $10 \%$ of food products on the Belgian market displayed Nutri-Score on the package, of which $75 \%$ displayed Nutri-Score A or B [3]. The Nutri-Score label is attributed according to the calculation of a single and overall score that takes into account for every $100 \mathrm{~g}$ or $100 \mathrm{~mL}$ of food product: the amount of nutrients that should be limited (energy, saturated fat, total sugar, sodium), and the amount of nutrients and foods that should be encouraged (fibers, proteins, fruits, vegetables, pulses, nuts, and rapeseed, walnut and olive oils). NutriScore rates the nutrient content of packaged foods with five colours/letters from red/E (least healthy) to green/A (most healthy) $[4,5]$.

A previous study among a convenience sample of 1007 Belgian consumers found that Nutri-Score was the most effective FOP to inform consumers about the overall nutritional quality of food products, compared to other existing government-endorsed FOP nutrition labels internationally [6]. Research on the impact of Nutri-Score on consumer purchases or diets has so far been experimental and evidence of real life impact is limited. In France, the impact of Nutri-Score on purchasing intentions has been investigated using a randomized controlled trial in a virtual web-based supermarket [7] as well as in an experimental physical supermarket environment reproducing a physical grocery shop [8]. In the web-based supermarket, the intervention simulated shopping situations with front-of-pack nutrition labels affixed on food products. Around 12,000 participants were randomly assigned to one of five exposure conditions: Guideline Daily Amounts, Multiple Traffic Lights (MTL), Nutri-Score, Green Tick, or control (no front-of-pack exposure). The Nutri-Score significantly led to the highest overall nutritional quality of the shopping basket, followed by
MTL and Green Tick, compared with the control, for all socio-economic groups. The Nutri-Score was also the only FOP label that led to significantly lower amounts in lipids, saturated fatty acids, and sodium of the shopping basket [7]. In the experimental supermarket, about 900 participants were recruited and distributed across three conditions: 1) control situation; 2) Application of the Nutri-Score on all breakfast cereals, sweet biscuits and appetizers; and 3) introduction of the Nutri-Score accompanied by consumer information on use and understanding of the label. Significantly higher mean nutritional quality was found of sweet biscuits purchased in the intervention combining the label and education, but not for the other food categories [8]. In a large multinational European cohort, consuming foods with a higher Food Standards Agency nutrient profiling system (FSAm-NPS) score (indicating lower nutritional quality), which grades the nutritional quality of food products and is used to derive Nutri-Score, was associated with a higher mortality from all causes and from cancer, as well as circulatory, respiratory, and digestive systems diseases [9].

Delhaize is one of the three grocery retailers with the largest market share (12.4\%) in Belgium according to Euromonitor market share data [10]. It is the first supermarket chain in Belgium as well as internationally which started rolling out electronic shelf labels (ESL) with Nutri-Score for all food products (including own brand and other products) in-store across stores since May 2019. Such a natural experiment allows to give insights into the potential impact of mandatory NutriScore FOP labelling on consumer purchases in Belgium, with the difference that the label is put on a shelf tag rather than on the product package (the latter is only voluntary) and that it is black rather than in colour. A recent systematic review found that point-of-sale interventions identifying healthy/unhealthy food options can lead to healthier customer purchasing behavior, particularly those delivered using shelf-labels or technology [11]. The review included three shelf labeling studies exploring two types of on-shelf nutrition guidance systems [Guiding Stars: food healthiness depicted through gold stars, and NuVal: overall nutrition score for a food product calculated on a scale of 1 (least healthy) to 100 (most healthy) dependent on the content of fat, saturated fat, sodium, protein, dietary fibre, and various vitamins and minerals]. All three studies concluded that these interventions led to improved overall healthiness of consumer purchasing [11].

The aim of this study was to evaluate the impact of ESL with Nutri-Score on consumer purchases, overall, as well as for different food categories, in supermarkets from a major Belgian retailer. 


\section{Methods}

\section{Study design}

This study was a controlled pre-to-post intervention assessment, which evaluated the impact of a real world retailer-initiated intervention on consumer food purchases. The researchers had no role in the design of this natural experiment. For this study, randomisation was not possible, but a group of control stores could be used for the evaluation, since the intervention was not rolled out in all Delhaize stores at the same time. A simple before-after analysis would not be valid as Delhaize began to implement Nutri-Score on food packages for its own brand products during the last quarter of 2018 . Other food manufacturers in Belgium also started implementing the Nutri-Score on the FOP in 2019. This means that the number of food products with Nutri-Score displayed on the FOP increased steadily over time, which implied the need of a controlled design in order to assess the effect of the ESL intervention.

\section{Description of the natural experiment}

Since May 2019 Delhaize began rolling out electronic shelf labels (ESL) with Nutri-Score across its stores. Unlike the Nutri-Score on the food packages, the ESL are in black and white (Fig. 1). The ESL are included on the shelf tags for all food products for sale in-store, not only the retailers' own brand products.

In addition to the ESL with Nutri-Score, Delhaize also ran national campaigns for Nutri-Score (in September 2018, January 2019 and September 2019), and offered price promotions in-store $[20 \%$ reductions on all Delhaize products with Nutri-Score A/B for all loyalty card holders (September-December 2019) and 50\% reductions on selected Delhaize products with NutriScore A/B, including fresh fruit and vegetables (MayAugust 2019)]. In this study the impact of the ESL was investigated over and above those other Nutri-Score related actions taken by the retailer.

\section{Selection of stores}

There are in total 128 Delhaize stores across the country (65 in Flanders, 41 in Wallonia and 22 in Brussels). The retailer grouped stores in six different clusters based on census data, customer data and confidential store level data: Affluent Suburban, Cities (Flanders), Cities (Wallonia), Highly Urban, Highly Urban - small basket, Town/Village (Flanders). For 11 of the 128 stores, the introduction of an ESL with Nutri-Score was not possible over the period 2019-2020 due to older technology used. All other stores started with ESL within the period from 22 May 2019 to 22 October 2019, of which most stores (81\%) started in June 2019 (Table 6 in Appendix 1).

The retailer confirmed that none of the stores had special issues (e.g. different portfolio of products, interventions on on-pack labelling and price promotions rolled out at different times/to a different extent to other stores, construction works) which were expected to affect the design of this study.

The retailer grouped all 128 stores by region, province and cluster (as explained above). For each store implementing the ESL in the period May-June 2019 $(N=112)$, it was evaluated whether a control store could be assigned from the same region, province and cluster, i.e. a store that either did not implement the ESL, or that implemented it at a later stage. In this way, pairs of intervention-control stores were formed. A control could be

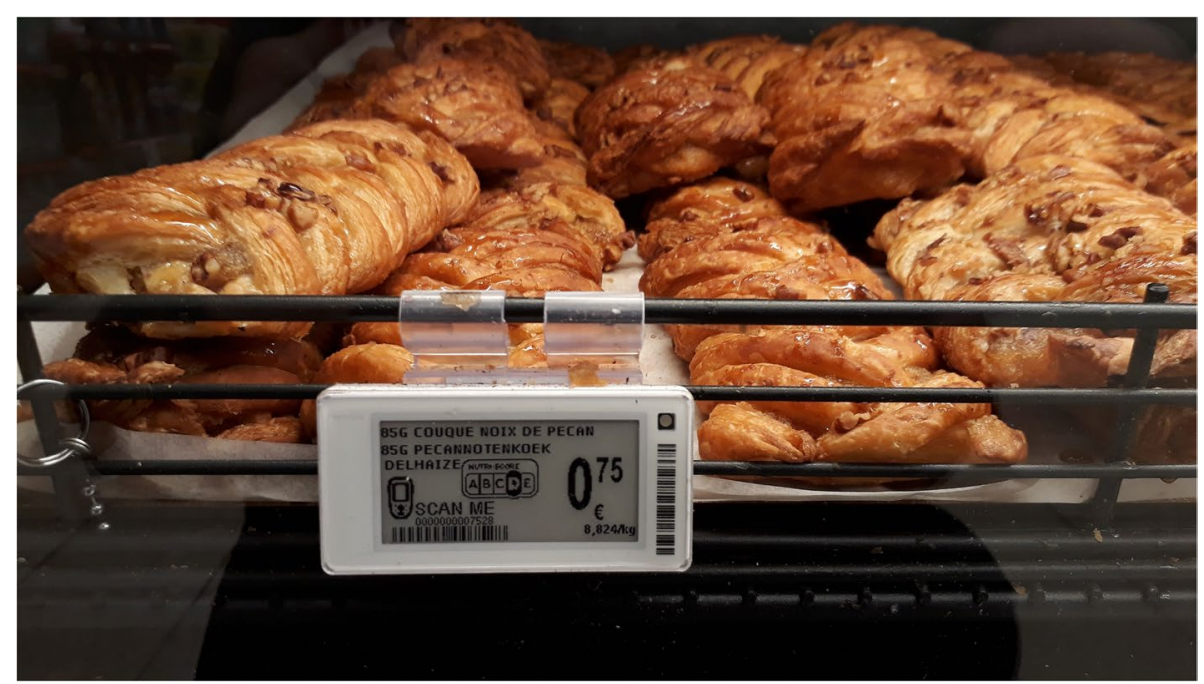

Fig. 1 Black and white display of the Nutri-Score on electronic shelf labels (ESL) in-store 
assigned to 43 of the 112 intervention stores. For some stores no control store could be assigned, because there was no store from the same region, province and cluster available with a later ESL implementation date, it was the only store available within the particular region, province and cluster or the implementation date of ESL was too close to implementation date of the ESL in the intervention store. Control stores were matched to more than one intervention store within the same region, province and cluster. In total there were 14 unique control stores with an ESL implementation date in September or October $2019(N=5)$ or with no ESL implementation $(N=9)$. For all 43 intervention stores, the ESL was implemented within a time frame of 3 weeks during May-June 2019 (27 May 2019-19 June 2019). The weekly sales for this period were excluded from the analysis.

\section{Food categories included}

The food categories included in this study are given in Appendix 2. They are based on the food classification system used by the retailer. The food categories are ranked by average proportion of sales out of total food sales for both intervention as well as control stores (Appendix 2). Out of the total of 75 available food categories, the assessment as part of this study excluded herbs and spices, hot drinks, alcoholic drinks, diet products and meal replacements, specific groups of ethnic foods, gluten free products, as well as food categories with less than 3 out 5 different Nutri-Score categories, keeping 58 food categories in total.

\section{Data received from the retailer}

For each store included in the study (43 intervention and 14 control stores), the weekly non-food and food sales data for the entire years 2018 and 2019 were obtained from the retailer by Nutri-Score allocation $(\mathrm{A} / \mathrm{B} / \mathrm{C} / \mathrm{D} / \mathrm{E})$ and by food category according to the existing retailer food classification system (Appendix 2). The pre-intervention period was defined from 01 January 2018 to 20 May 2019 and the post-intervention period was defined from 27 June to 31 December 2019. According to the retailer any missing data for Nutri-Score on shelf labels were limited to less than $5 \%$ of the food and beverage products in scope for a Nutri-Score label. Since the same products are sold nationally in all Delhaize stores and since the data is centrally controlled, these missing data are similar for all stores at any time.

\section{Outcomes}

The primary outcome measures assessed in this study were:

- \% of total food sales for products with Nutri-Score A, B, C, D and E overall
Secondary outcome measures assessed in the study were:

- \% of sales for food products with Nutri-Score A, B, C, $\mathrm{D}$ and $\mathrm{E}$ within food category

- \% of sales for food products with Nutri-Score A, B, C, $\mathrm{D}$ and $\mathrm{E}$ by food category

\section{Data analysis}

This study is a controlled pre-to-post intervention assessment. Difference-in-differences regression analysis was used to estimate the effect of the ESL intervention on proportion of food sales for Nutri-Score A,B,C,D,E. Such quasi-experimental method is increasingly used to evaluate the impact of interventions which could not be randomized [12]. We used linear mixed models to account for clustering at store-level over time. The model allowed for flexible time trends using binary variables for each week. We controlled for characteristics of the stores, including, region, cluster type, and total non-food sales (as a proxy for the size of the stores). Analyses were conducted for overall food sales, as well as by food category. In the model results, if the difference-in-difference coefficient estimate is statistically significant, it is likely the slopes in the control and intervention group are not parallel after the intervention, and so the exposure has affected the outcome in the exposed group differently than the underlying background trend, as captured by the unexposed group.

Analyses were weighted to re-balance the discrepancy between the number of intervention stores $(N=43)$ and controls $(N=14)$. Weights were assigned to each control store to reflect the frequency with which they were matched with a particular intervention store $(x / 43)$. The intervention stores all received the same weight $(1 / 43)$.

In order to account for multiple testing, a Bonferroni adjustment was applied as the same analysis was repeated for multiple food categories. Therefore, the $p$-value was considered statistically significant if lower than 0.0008 (i.e. 0.05/58).

Significant substitutions $(p<0.0008)$ between NutriScore allocations (i.e. significant decrease in B and similar significant increase in A) within food categories were identified. The data were analyzed using SAS 9.4.

\section{Results}

\section{Description of stores included in the study}

The study included 43 intervention stores and 14 control stores. While weekly sales data for the entire years 2018 and 2019 were available for all included stores, for some stores the intervention period was shorter due to the 
Table 1 Description of intervention and control stores included in the study, as well as the stores not included

\begin{tabular}{|c|c|c|c|c|}
\hline & & $\begin{array}{l}\text { Intervention stores } \\
(N=43)\end{array}$ & Control stores $(N=14)$ & $\begin{array}{l}\text { Stores not } \\
\text { included } \\
(N=71)\end{array}$ \\
\hline \multirow[t]{3}{*}{ Region } & Brussels & 9 & 1 & 12 \\
\hline & Flanders & 19 & 6 & 40 \\
\hline & Wallonia & 15 & 7 & 19 \\
\hline \multirow[t]{11}{*}{ Province } & Antwerpen & 3 & 1 & 16 \\
\hline & Brabant Wallon & 1 & 1 & 6 \\
\hline & Brussels & 9 & 1 & 12 \\
\hline & Hainaut & 8 & 3 & 1 \\
\hline & Limburg & 3 & 1 & 1 \\
\hline & Liège & 2 & 1 & 11 \\
\hline & Luxembourg & 1 & 1 & 1 \\
\hline & Namur & 3 & 1 & 0 \\
\hline & Oost-Vlaanderen & 0 & 0 & 13 \\
\hline & Vlaams-Brabant & 6 & 2 & 7 \\
\hline & West-Vlaanderen & 7 & 2 & 3 \\
\hline \multirow[t]{6}{*}{ Cluster } & Affluent Suburban & 5 & 1 & 11 \\
\hline & Cities (Flanders) & 8 & 3 & 11 \\
\hline & Cities (Wallonia) & 13 & 6 & 12 \\
\hline & Highly Urban & 0 & 0 & 18 \\
\hline & Highly Urban - Small basket & 11 & 2 & 5 \\
\hline & Town/Village (Flanders) & 6 & 2 & 14 \\
\hline \multirow[t]{3}{*}{ ESL implementation } & 2019 & 43 & & \\
\hline & May $2019(27-05 / 19-31 / 05 / 19)$ & 3 & & \\
\hline & June 2019 (01/06/19-19/06/19) & 40 & & \\
\hline \multirow{4}{*}{$\begin{array}{l}\text { Intervention period taken into } \\
\text { account (days) }\end{array}$} & Min & 85 & & \\
\hline & Max & 218 & & \\
\hline & Mean & 173 & & \\
\hline & Standard Deviation & 47 & & \\
\hline
\end{tabular}

implementation of ESL in the control store at a later date in 2019 (Table 1).

There were no baseline differences between intervention and control stores with regard to the proportion of food sales for different Nutri-Score categories, across the different seasons (Table 2).

Impact of ESL on proportion of total food sales for Nutri-score A, B, C, D, E overall, adjusted for region, cluster, week of the year and total non-food sales

Table 3 shows the overall results from the difference-indifference analysis. There was no evidence of differences in the proportion of total food sales for Nutri-Score A, B, $\mathrm{C}, \mathrm{D}$ and $\mathrm{E}$ between intervention and control stores prior to the intervention (Table 3).

According to the unadjusted results, there were no significant impacts of the ESL intervention on the proportion of total food sales for Nutri-Score A, B, C, D or E, neither when the analyses were adjusted for region, cluster and total non-food sales.
When the analyses were also adjusted for week of the year, comparing pre- and post-intervention periods, difference-in-differences for the proportion of total sales for Nutri-Score B and C products were more favourable in the intervention stores than the control stores $(0.11 \pm 0.04 \%, p=0.007$ and $-0.06 \pm 0.03 \%$, $p=0.026$ respectively). The decrease in proportion of sales for Nutri-Score B products from before to after was smaller in the intervention stores (from $13.6 \pm 0.1 \%$ to $13.1 \pm 0.6 \%)$ than the control stores (from $13.7 \pm 0.2 \%$ to $13.1 \pm 0.6 \%$ ), while the decrease in proportion of sales for Nutri-Score C products was greater in the intervention stores (from $13.8 \pm 0.2 \%$ to $13.6 \pm 0.4 \%$ ) than in the control stores (from $13.7 \pm 0.2 \%$ to $13.7 \pm 0.4 \%)$. Comparing pre- and postintervention periods, difference-in-differences for the proportion of total sales for Nutri-Score D products were less favourable in the intervention stores than the control stores $(0.12 \pm 0.04 \%, p=0.002)$. There was a decrease in proportion of sales for Nutri-Score 
Table 2 Baseline differences between control and intervention stores for average proportion $(95 \% \mathrm{Cl})$ of total weekly food sales for Nutri-Score A,B,C,D,E by season (year $=2018$ )

\begin{tabular}{|c|c|c|c|}
\hline \multicolumn{2}{|c|}{ Control stores $(N=14)^{\mathrm{a}}$} & \multicolumn{2}{|c|}{ Intervention stores $(N=43)$} \\
\hline \multicolumn{2}{|l|}{ Winter } & \multicolumn{2}{|c|}{ Winter } \\
\hline$A$ & $33.3(32.4-34.1)$ & A & $34.1(33.1-35.1)$ \\
\hline B & $19.8(19.4-20.2)$ & B & $19.6(19.2-20.0)$ \\
\hline C & $14.3(14.2-14.5)$ & C & $14.1(13.9-14.3)$ \\
\hline$D$ & $26.3(25.6-27.0)$ & $D$ & $27.6(23.0-32.1)$ \\
\hline E & $15.0(14.6-15.3)$ & E & $14.4(14.0-14.8)$ \\
\hline \multicolumn{2}{|l|}{ Spring } & \multicolumn{2}{|c|}{ Spring } \\
\hline$A$ & $42.6(41.7-43.5)$ & A & $42.9(41.6-44.1)$ \\
\hline$B$ & $16.5(16.2-16.9)$ & B & $16.2(15.8-16.6)$ \\
\hline C & $17.5(17.2-17.8)$ & C & $17.1(16.7-17.5)$ \\
\hline$D$ & $25.8(25.2-26.3)$ & $D$ & $24.9(24.3-25.5)$ \\
\hline E & $12.6(12.2-12.9)$ & E & $12.1(11.8-12.5)$ \\
\hline \multicolumn{2}{|l|}{ Summer } & \multicolumn{2}{|c|}{ Summer } \\
\hline$A$ & $40.0(39.4-40.6)$ & A & $40.9(38.4-43.3)$ \\
\hline B & $17.1(16.7-17.5)$ & B & $16.9(16.0-17.8)$ \\
\hline$C$ & $17.7(17.4-18.0)$ & $C$ & $17.8(16.7-18.9)$ \\
\hline$D$ & $25.5(25.0-26.1)$ & $D$ & $25.2(23.8-26.5)$ \\
\hline E & $12.8(12.5-13.2)$ & E & $12.5(11.7-13.3)$ \\
\hline \multicolumn{2}{|l|}{ Autumn } & \multicolumn{2}{|c|}{ Autumn } \\
\hline$A$ & $43.2(42.4-44.1)$ & A & $44.6(43.6-45.7)$ \\
\hline$B$ & $18.7(18.2-19.2)$ & B & $18.3(17.9-18.7)$ \\
\hline C & $19.3(19.0-19.6)$ & C & $19.4(19.0-19.7)$ \\
\hline$D$ & $30.2(29.4-30.9)$ & $D$ & $29.8(29.1-30.4)$ \\
\hline E & $15.4(15.1-15.8)$ & E & $15.1(14.7-15.5)$ \\
\hline
\end{tabular}

${ }^{a}$ Averages across stores taken, some stores get a higher weight as they are control store to multiple intervention stores

Seasons: winter (Jan/Feb/March), spring (April/May/June), summer (July/August/ September) and autumn (October, November, December)

D products from before to after in the control stores (from $21.0 \pm 0.2 \%$ to $20.9 \pm 0.5 \%$ ) but not in the intervention stores (from $20.8 \pm 0.2 \%$ to $20.8 \pm 0.5 \%$ ) (Table 3).

Impact of ESL on proportion of sales of Nutri-score A, B, C, $D$, E products within food category, adjusted for region, cluster, week of the year and total non-food sales

The difference-in-difference coefficients for the impact of ESL on proportion of sales of Nutri-Score A, B, C, D, $\mathrm{E}$ products within food category, adjusted for region, cluster, week of the year and total non-food sales, by food category and Nutri-Score category are shown in Table 4. The unadjusted results can be found in Appendix 3.

The mean change in the proportion of the food sales for Nutri-Score A within food category from before to after, adjusted for region, cluster, non-food sales and week of the year, was significantly higher $(p<0.0008)$ for intervention than control stores for poultry, rabbit and exotic meat $(1.30 \pm 0.22 \%)$, canned fish and meat $(0.71 \pm 0.20 \%)$, meals to go (i.e. wraps sandwiches) $(1.18 \pm 0.23 \%)$, confectionery $(0.20 \pm 0.05 \%)$, ready to use fresh vegetables and potatoes $(0.40 \pm 0.07 \%)$, frozen French fries and potato products $(0.85 \pm 0.24 \%)$, and fresh fruit $(0.04 \pm 0.01 \%)$. Similar mean changes were noted for other food categories (yoghurt, soft white cheese and desserts, canned soups, frozen vegetables and soups) but these weren't statistically significant after the Bonferroni correction $(p<0.05$ but $>0.0008)$ (Table 4).

The mean change in the proportion of the food sales for Nutri-Score B within food category from before to after, adjusted for covariates, was significantly higher $(p<0.0008)$ for intervention than control stores for bread $(3.07 \pm 0.33 \%)$, meals to compose $(2.07 \pm 0.36 \%)$, sugar and sweeteners $(0.80 \pm 0.22 \%)$, dried fruit including nuts $(1.72 \pm 0.33 \%)$ and chilled vegetarian products $(1.02 \pm 0.21 \%)$ (Table 4$)$. Similar mean changes were noted for other food categories (fresh crustaceans and mollusks, ice-cream and frozen desserts, syrups, canned fruit) but these weren't statistically significant after the Bonferroni correction $(p<0.05$ but $>0.0008)$ (Table 4).

The mean change in the proportion of the food sales for Nutri-Score D within food category from before to after was significantly lower $(p<0.0008)$ for intervention than control stores for marinated fish and shell fish $(-1.34 \pm 0.39 \%)$, Viennese cakes and buns $(-1.24 \pm 0.28 \%)$, prepared meals canned ambient $(-2.13 \pm 0.47 \%)$, confectionery $(-1.01 \pm 0.24 \%)$, and sugar and sweeteners $(-1.12 \pm 0.26 \%)$ (Table 4$)$.

Similar mean changes were noted for other food categories (poultry rabbit and exotic meat, waters (including flavoured), meals to compose, oil and vinegar, canned soups, ready to use vegetables and potatoes) but these weren't statistically significant after the Bonferroni correction $(p<0.05$ but $>0.0008)$ (Table 4$)$.

The mean change in the proportion of the food sales for Nutri-Score E within food category from before to after was significantly lower $(p<0.0008)$ for intervention than control stores for cheeses $(-0.21 \pm 0.04 \%)$, yoghurt, soft white cheese and desserts $(-0.19 \pm 0.05 \%)$, ingredients dairy $(-0.20 \pm 0.06 \%), \%)$, juices fresh chilled $(-0.53 \pm 0.11 \%)$, sweet bread toppings $(-0.65 \pm 0.17 \%)$, dried fruit $(-0.09 \pm 0.02 \%)$ and world food $(-0.94 \pm 0.18 \%)$ (Table 4$)$. Similar mean changes were noted for other food categories (processed fish, diet products, meal replacements, special foods and syrups) but these weren't statistically significant after the Bonferroni correction $(p<0.05$ but $>0.0008$ ) (Table 4). 
Table 3 Impact of ESL on proportion of total weekly food sales for Nutri-Score A, B, C, D, E products, unadjusted and adjusted for region, cluster, week of the year and total non-food sales

\begin{tabular}{|c|c|c|c|c|c|c|c|}
\hline \multirow[b]{3}{*}{ Nutri-Score } & \multicolumn{4}{|c|}{$\%$ (SE) of total food sales } & \multirow{3}{*}{$\begin{array}{l}p \\
\text { baseline diff }\end{array}$} & \multirow{2}{*}{\multicolumn{2}{|c|}{ diff-in-diff }} \\
\hline & \multicolumn{2}{|l|}{ control } & \multicolumn{2}{|c|}{ intervention } & & & \\
\hline & before & after & before & after & & coeff $^{2}(\mathrm{SE})$ & $\mathrm{p}$ \\
\hline & Unadjustec & & & & & & \\
\hline A & $32.9 \pm 0.5$ & $32.3 \pm 0.6$ & $33.7 \pm 0.3$ & $33.0 \pm 0.4$ & 0.173 & $-0.05 \pm 0.52$ & 0.928 \\
\hline B & $13.5 \pm 0.1$ & $13.8 \pm 0.2$ & $13.4 \pm 0.1$ & $13.7 \pm 0.1$ & 0.370 & $0.08 \pm 0.21$ & 0.718 \\
\hline C & $13.9 \pm 0.1$ & $13.8 \pm 0.1$ & $13.8 \pm 0.1$ & $13.7 \pm 0.1$ & 0.834 & $-0.06 \pm 0.21$ & 0.776 \\
\hline $\mathrm{D}$ & $20.8 \pm 0.3$ & $21.4 \pm 0.3$ & $20.4 \pm 0.2$ & $21.1 \pm 0.2$ & 0.258 & $0.09 \pm 0.32$ & 0.786 \\
\hline \multirow[t]{2}{*}{$\mathrm{E}$} & $10.5 \pm 0.2$ & $10.6 \pm 0.2$ & $10.3 \pm 0.1$ & $10.5 \pm 0.1$ & 0.262 & $0.05 \pm 0.16$ & 0.773 \\
\hline & \multicolumn{7}{|c|}{ Adjusted for region, cluster and total non-food sales } \\
\hline A & $33.1 \pm 0.4$ & $32.8 \pm 0.5$ & $34.0 \pm 0.3$ & $33.8 \pm 0.4$ & 0.058 & $0.11 \pm 0.52$ & 0.832 \\
\hline B & $13.4 \pm 0.1$ & $13.9 \pm 0.2$ & $13.5 \pm 0.1$ & $14.1 \pm 0.2$ & 0.884 & $0.16 \pm 0.21$ & 0.450 \\
\hline C & $13.8 \pm 0.1$ & $13.8 \pm 0.1$ & $13.8 \pm 0.1$ & $13.8 \pm 0.1$ & 0.746 & $-0.03 \pm 0.21$ & 0.898 \\
\hline $\mathrm{D}$ & $20.9 \pm 0.1$ & $21.6 \pm 0.2$ & $20.6 \pm 0.1$ & $21.5 \pm 0.2$ & 0.132 & $0.16 \pm 0.31$ & 0.615 \\
\hline \multirow[t]{2}{*}{$\mathrm{E}$} & $10.3 \pm 0.1$ & $10.5 \pm 0.1$ & $10.3 \pm 0.1$ & $10.5 \pm 0.1$ & 0.597 & $0.07 \pm 0.16$ & 0.669 \\
\hline & \multicolumn{7}{|c|}{ Adjusted for region, cluster, total non-food sales and week of the year } \\
\hline A & $32.9 \pm 0.5$ & $33.4 \pm 1.0$ & $33.3 \pm 0.4$ & $33.7 \pm 0.9$ & 0.316 & $-0.09 \pm 0.06$ & 0.176 \\
\hline B & $13.7 \pm 0.2$ & $13.1 \pm 0.6$ & $13.6 \pm 0.1$ & $13.1 \pm 0.6$ & 0.521 & $0.11 \pm 0.04$ & 0.007 \\
\hline C & $13.7 \pm 0.2$ & $13.7 \pm 0.4$ & $13.8 \pm 0.2$ & $13.6 \pm 0.4$ & 0.856 & $-0.06 \pm 0.03$ & 0.026 \\
\hline $\mathrm{D}$ & $21.0 \pm 0.2$ & $20.9 \pm 0.5$ & $20.8 \pm 0.2$ & $20.8 \pm 0.5$ & 0.144 & $0.12 \pm 0.04$ & 0.002 \\
\hline$E$ & $10.4 \pm 0.2$ & $10.3 \pm 0.5$ & $10.3 \pm 0.2$ & $10.3 \pm 0.5$ & 0.546 & $0.04 \pm 0.03$ & 0.265 \\
\hline
\end{tabular}

${ }^{1} p$-value for mean difference in outcome between intervention and control groups prior to the intervention (existing baseline differences)

${ }^{2}$ Difference in difference estimator. It shows whether the expected mean change in \% total sales for Nutri-Score $A, B, C, D, E$ from before to after was different between control and intervention stores

Based on this analysis within food categories, favourable significant substitutions in proportion of sales towards healthier versions of food products were found for poultry, rabbit and exotic meat (Nutri-Score $\mathrm{C}$ to A), marinated fish and shell fish (Nutri-Score D to C), yoghurt, soft white cheeses and desserts (NutriScore E to D), juices fresh chilled (Nutri-Score E to C), Meals to go (i.e. wraps, salads, sandwiches) (NutriScore B to A), meals to compose (Nutri-Score C to B), prepared meals canned ambient (Nutri-Score D to C), Sweet bread toppings (chocolate, jam, honey, pinda) (Nutri-Score E to C), confectionery (Nutri-Score D to A), sugar and sweeteners (Nutri-Score D to B), Readyto-use fresh vegetables, including potatoes (NutriScore B, C to A), fresh fruit (Nutri-Score B, C to A), and dried fruit including nuts (Nutri-Score $\mathrm{C}, \mathrm{E}$ to $\mathrm{B}$ ) (Table 4).

There were also some unfavourable significant substitutions for the food categories processed meat (Nutri-Score $B$ to $C$ ), bread (Nutri-Score A to B), cakes and pastries (Nutri-Score B, C to E), Viennese cakes and buns (NutriScore $\mathrm{D}$ to $\mathrm{E}$ ) and chilled vegetarian products (NutriScore A to B) (Table 4).
Impact of ESL on proportion of total sales of Nutri-score $A$, $B, C, D, E$ products by food category, adjusted for region, cluster, week of the year and total non-food sales

Table 5 shows the difference in difference coefficients adjusted for region, cluster, non-food sales and week of the year for the expected mean change in the proportion of total food sales for Nutri-Score A products, NutriScore B products, Nutri-Score C products, Nutri-Score D products and Nutri-Score E products by food category from before to after the ESL intervention.

The mean change in the proportion of total food sales for Nutri-Score A products from before to after was higher $(p<0.0008)$ for intervention than control stores for the following food categories: Frozen French fries and potato products, frozen vegetables and soups and Apero Corner chilled (cheese, salami, humus, olives etc.). The opposite was found for ice-cream and frozen desserts, ambient fruit juices, bread, sweet biscuits and Aperitif snacks (i.e. chips, salted biscuits) (Table 5).

The mean change in the proportion of total food sales for Nutri-Score B products from before to after was higher $(p<0.0008)$ for intervention than control stores 
Table 4 Impact of ESL on proportion of weekly sales for Nutri-Score A, B, C, D, E products within food category, by food category, adjusted for region, cluster, week and non-food sales

\begin{tabular}{|c|c|c|c|c|c|c|c|c|c|c|}
\hline \multirow{3}{*}{ Broad food category } & \multicolumn{4}{|c|}{ mean (SE) \% total sales } & \multicolumn{5}{|c|}{$\%$ diff-in-diff in proportion of weekly sales within the food category } & \multirow{3}{*}{ Substitution* } \\
\hline & \multicolumn{2}{|c|}{ intervention } & \multicolumn{2}{|c|}{ control } & \multirow{2}{*}{$\begin{array}{c}\text { A } \\
\operatorname{diff}(\mathrm{SE})\end{array}$} & B & c & D & E & \\
\hline & mean & SE & mean & SE & & $\operatorname{diff}(\mathrm{SE})$ & $\operatorname{diff}(\mathrm{SE})$ & $\operatorname{diff}(\mathrm{SE})$ & $\operatorname{diff}(\mathrm{SE})$ & \\
\hline Meat, fish, eggs and related products & & & & & & & & & & \\
\hline Fresh packaged meat & 8,80 & 0,05 & 8,75 & 0,03 & $-0,56(0,29)$ & $0,08(0,23)$ & $0,21(0,11)$ & $0,16(0,15)$ & $0,13(0,05)$ & \\
\hline Processed meat (charcuterie) & 5,54 & 0,03 & 5,43 & 0,01 & $0,03(0,02)$ & $-0,56(0,06)$ & $0,73(0,15)$ & $-0,07(0,14)$ & $-0,09(0,15)$ & $B-->C$ \\
\hline Poultry, rabbit and exotic meat & 3,66 & 0,02 & 3,59 & 0,01 & $1,30(0,22)$ & $-0,33(0,16)$ & $-0,76(0,17)$ & $-0,22(0,07)$ & $0,00(0,02)$ & C- $>A$ \\
\hline Fresh fish & 3,45 & 0,02 & 3,37 & 0,01 & $-0,10(0,18)$ & $0,12(0,10)$ & $-0,09(0,08)$ & $0,07(0,12)$ & / & \\
\hline Processed fish & 1,24 & 0,01 & 1,25 & 0,01 & / & $-0,02(0,12)$ & $-0,09(0,10)$ & $0,15(0,16)$ & $-0,04(0,02)$ & \\
\hline Shrimps & 1,09 & 0,02 & 1,10 & 0,01 & $-0,21(0,07)$ & $0,16(0,29)$ & $0,19(0,31)$ & $-0,11(0,06)$ & / & \\
\hline Frozen meat, fish, crustaceans & 0,93 & 0,01 & 0,90 & 0,00 & $-0,56(0,29)$ & $0,08(0,23)$ & $0,21(0,11)$ & $0,16(0,15)$ & $0,13(0,05)$ & \\
\hline Eggs and egg products & 0,83 & 0,00 & 0,88 & 0,00 & $0,34(0,27)$ & $-0,38(0,28)$ & I & $0,07(0,05)$ & 1 & \\
\hline Canned fish and meat & 0,76 & 0,01 & 0,75 & 0,00 & $0,71(0,20)$ & $-0,74(0,32)$ & $0,14(0,18)$ & $-0,16(0,31)$ & $0,06(0,07)$ & \\
\hline Fresh crustaceans and mollusks & 0,66 & 0,02 & 0,66 & 0,01 & $-1,20(0,56)$ & $1,31(0,58)$ & $0,55(0,48)$ & $-0,13(0,09)$ & $0,02(0,04)$ & \\
\hline Game & 0,37 & 0,02 & 0,42 & 0,01 & $-1,20(0,99)$ & $0,33(0,85)$ & $2,99(1,15)$ & $-0,82(0,73)$ & / & \\
\hline Marinated fish and shellfish & 0,19 & 0,00 & 0,18 & 0,00 & $0,20(0,14)$ & $-0,25(0,12)$ & $1,36(0,36)$ & $-1,34(0,39)$ & / & $D-->C$ \\
\hline Cheeses and dairy products & & & & & & & & & & \\
\hline Cheeses & 6,39 & 0,03 & 6,33 & 0,01 & $-0,01(0,01)$ & I & $0,03(0,05)$ & $0,19(0,06)$ & $-0,21(0,04)$ & \\
\hline Yoghurt, soft white cheese and desserts & 3,58 & 0,02 & 3,60 & 0,01 & $0,19(0,08)$ & $-0,04(0,11)$ & $-0,24(0,11)$ & $0,26(0,07)$ & $-0,19(0,05)$ & $E->D$ \\
\hline Milk UHT / fresh and plant-based drinks & 1,50 & 0,01 & 1,51 & 0,01 & $0,16(0,15)$ & $-0,50(0,17)$ & $0,11(0,09)$ & $0,20(0,05)$ & l & \\
\hline Ice-cream and frozen desserts & 1,38 & 0,02 & 1,41 & 0,01 & $-0,31(0,08)$ & $0,35(0,11)$ & $0,13(0,17)$ & $-0,16(0,22)$ & $-0,00(0,13)$ & \\
\hline Ingredients dairy & 1,08 & 0,01 & 1,06 & 0,00 & $-1,40(0,65)$ & $0,04(0,07)$ & $-0,89(0,17)$ & $1,23(0,18)$ & $-0,20(0,06)$ & $C / E \rightarrow D$ \\
\hline Beverages & & & & & & & & & & \\
\hline Soft drinks (light, zero, regular) & 4,93 & 0,03 & 4,83 & 0,03 & $-0,02(0,01)$ & $0,14(0,12)$ & $-0,39(0,06)$ & $0,25(0,13)$ & $0,01(0,15)$ & \\
\hline Waters (including flavoured) & 2,70 & 0,02 & 2,72 & 0,01 & $0,11(0,09)$ & $-0,18(0,09)$ & l & $-0,12(0,06)$ & $-0,05(0,03)$ & \\
\hline Fruit juices, ambient & 0,63 & 0,00 & 0,64 & 0,00 & $-0,97(0,17)$ & $-0,05(0,09)$ & $0,87(0,26)$ & $0,38(0,11)$ & $-0,25(0,20)$ & \\
\hline Juices, fresh, chilled & 0,55 & 0,01 & 0,67 & 0,00 & / & $-0,22(0,08)$ & $0,93(0,21)$ & $-0,19(0,16)$ & $-0,53(0,11)$ & $E-->C$ \\
\hline Non-alcoholic drinks & 0,09 & 0,00 & 0,09 & 0,00 & I & $0,38(1,00)$ & $-0,14(0,46)$ & $-0,50(1,06)$ & $0,31(0,91)$ & \\
\hline Bread and bakery products & & & & & & & & & & \\
\hline Bread & 4,05 & 0,03 & 4,05 & 0,01 & $-2,52(0,31)$ & $3,07(0,33)$ & $-0,32(0,11)$ & $-0,22(0,13)$ & $-0,01(0,02)$ & $A->B$ \\
\hline Sweet biscuits & 2,26 & 0,08 & 2,16 & 0,01 & $-0,05(0,01)$ & $-0,04(0,02)$ & $0,03(0,14)$ & $-0,16(0,13)$ & $0,49(0,14)$ & $A \rightarrow E$ \\
\hline Cakes and pastries & 2,03 & 0,02 & 2,01 & 0,01 & / & $-0,60(0,06)$ & $-0,75(0,21)$ & $-0,39(0,24)$ & $1,49(0,29)$ & $B / C-->E$ \\
\hline Viennese cakes and buns & 0,52 & 0,01 & 0,55 & 0,00 & / & l & $0,16(0,09)$ & $-1,24(0,28)$ & $1,02(0,28)$ & $D-->E$ \\
\hline Bread preparations (i.e. crackers, rusks) & 0,26 & 0,00 & 0,25 & 0,00 & $-0,08(0,19)$ & $0,02(0,18)$ & $-0,83(0,27)$ & $0,67(0,23)$ & $0,23(0,17)$ & \\
\hline Grains and cereals & & & & & & & & & & \\
\hline Pasta, rice and starch products & 1,12 & 0,01 & 1,11 & 0,00 & $-0,06(0,14)$ & $0,15(0,11)$ & $-0,16(0,09)$ & $0,08(0,04)$ & I & \\
\hline Breakfast cereals & 0,76 & 0,01 & 0,81 & 0,00 & $-0,14(0,17)$ & $-0,34(0,12)$ & $-0,03(0,21)$ & $0,19(0,19)$ & $0,20(0,09)$ & \\
\hline Prepared and convenience meals & & & & & & & & & & \\
\hline Meals to cook and heat (i.e. lasagna, goulash) & 2,44 & 0,02 & 2,32 & 0,01 & $0,18(0,17)$ & $-0,05(0,18)$ & $0,05(0,16)$ & $-0,15(0,14)$ & $-0,03(0,02)$ & \\
\hline Meals to go (i.e. wraps, salads, sandwiches) & 1,19 & 0,01 & 1,24 & 0,01 & $1,18(0,23)$ & $-1,04(0,21)$ & $-0,19(0,23)$ & $0,16(0,04)$ & $-0,04(0,04)$ & $B->A$ \\
\hline Frozen pizzas and prepared meals & 0,89 & 0,01 & 0,88 & 0,00 & $0,10(0,09)$ & $-0,46(0,19)$ & $-0,61(0,20)$ & $0,99(0,18)$ & $-0,01(0,04)$ & \\
\hline Meals to compose & 0,38 & 0,00 & 0,41 & 0,00 & $0,26(0,17)$ & $2,07(0,36)$ & $-2,22(0,37)$ & $-0,27(0,09)$ & / & C-->B \\
\hline Meals concept \& event & 0,33 & 0,00 & 0,38 & 0,00 & / & $-0,60(0,16)$ & $0,12(0,32)$ & $1,29(0,28)$ & / & $B-->D$ \\
\hline Prepared meals canned ambient & 0,15 & 0,00 & 0,13 & 0,00 & $-0,30(0,48)$ & $-1,58(0,50)$ & $2,14(0,40)$ & $-2,13(0,47)$ & I & $D-\rightarrow C$ \\
\hline Chocolate, sugar and confectionery & & & & & & & & & & \\
\hline Chocolate, including bars & 1,90 & 0,02 & 1,84 & 0,01 & / & / & $0,08(0,07)$ & $0,19(0,09)$ & $-0,18(0,09)$ & \\
\hline Sweet bread toppings (chocolate, jam, honey, pinda) & 0,94 & 0,01 & 0,93 & 0,00 & $0,02(0,05)$ & $0,09(0,06)$ & $0,48(0,14)$ & $0,04(0,18)$ & $-0,65(0,17)$ & $E-->C$ \\
\hline Confectionery & 0,86 & 0,01 & 0,80 & 0,01 & $0,20(0,05)$ & $0,01(0,17)$ & $0,30(0,10)$ & $-1,01(0,24)$ & $0,54(0,20)$ & D-->A \\
\hline Sugar and sweeteners & 0,30 & 0,00 & 0,30 & 0,00 & / & $0,80(0,22)$ & $0,29(0,17)$ & $-1,12(0,26)$ & $1,08(1,62)$ & D-->B \\
\hline Syrups & 0,23 & 0,00 & 0,21 & 0,00 & / & $0,52(0,23)$ & $1,21(0,46)$ & $-0,36(0,20)$ & $-1,07(0,49)$ & \\
\hline Fats and oils & & & & & & & & & & \\
\hline$\overline{\text { Spreadable fats (i.e. butter, margarines) }}$ & 1,75 & 0,01 & 1,66 & 0,00 & / & l & $-0,49(0,10)$ & $0,07(0,14)$ & $0,43(0,15)$ & \\
\hline Oil and vinegar & 0,73 & 0,01 & 0,72 & 0,00 & $-0,13(0,26)$ & $-0,01(0,26)$ & $0,57(0,22)$ & $-0,73(0,23)$ & $0,25(0,07)$ & \\
\hline Savoury snacks & & & & & & & & & & \\
\hline Aperitif snacks (i.e. chips, salted biscuits) & 1,68 & 0,01 & 1,64 & 0,00 & $-0,30(0,06)$ & $-0,12(0,04)$ & $0,29(0,14)$ & $0,15(0,14)$ & $-0,02(0,09)$ & \\
\hline Condiments, soups and sauces & & & & & & & & & & \\
\hline Condiments and sauces & 1,37 & 0,01 & 1,31 & 0,00 & $-0,01(0,09)$ & $0,13(0,08)$ & $-0,24(0,13)$ & $0,27(0,15)$ & $-0,15(0,09)$ & \\
\hline Soups, canned & 0,45 & 0,00 & 0,41 & 0,00 & $0,20(0,10)$ & $-0,38(0,27)$ & $0,22(0,27)$ & $-0,22(0,08)$ & $0,16(0,07)$ & \\
\hline Vegetables & & & & & & & & & & \\
\hline$\overline{\text { Ready-to-use fresh vegetables, including potatoes }}$ & 1,27 & 0,01 & 1,28 & 0,00 & $0,40(0,07)$ & $-0,18(0,04)$ & $-0,14(0,04)$ & $-0,07(0,03)$ & / & $B / C-->A$ \\
\hline Canned vegetables & 0,99 & 0,01 & 0,95 & 0,00 & $-0,06(0,06)$ & $-0,01(0,05)$ & $0,07(0,04)$ & / & / & \\
\hline Frozen French fries and potato products & 0,62 & 0,00 & 0,59 & 0,00 & $0,85(0,24)$ & $-0,51(0,23)$ & $-0,49(0,15)$ & $0,15(0,12)$ & l & \\
\hline Frozen vegetables and soups & 0,59 & 0,01 & 0,57 & 0,00 & $0,56(0,17)$ & $-0,70(0,14)$ & $0,13(0,10)$ & / & $0,10(0,06)$ & \\
\hline Fruits & & & & & & & & & & \\
\hline$\overline{\text { Fresh fruit }}$ & 7,83 & 0,05 & 8,21 & 0,03 & $0,04(0,01)$ & $-0,00(0,00)$ & $-0,04(0,01)$ & / & l & C/B $\rightarrow>A$ \\
\hline Dried fruit (including nuts) & 0,79 & 0,01 & 0,87 & 0,00 & $-0,71(0,26)$ & $1,72(0,33)$ & $-1,25(0,23)$ & $0,29(0,13)$ & $-0,09(0,02)$ & C/E-->B \\
\hline Canned fruit & 0,43 & 0,00 & 0,39 & 0,00 & $-0,24(0,25)$ & $0,60(0,21)$ & $-0,41(0,17)$ & $0,20(0,10)$ & / & \\
\hline Miscellaneous & & & & & & & & & & \\
\hline$\overline{\text { Apero Corner, chilled (cheese, salami, humus, olives etc.) }}$ & 0,73 & 0,01 & 0,84 & 0,01 & $0,02(0,37)$ & $-0,28(0,24)$ & $-0,61(0,31)$ & $0,34(0,35)$ & $-0,01(0,23)$ & \\
\hline Spreadable salads (i.e. meat, crab, etc.) & 0,67 & 0,00 & 0,65 & 0,00 & / & $-0,17(0,12)$ & $0,38(0,17)$ & $-0,23(0,19)$ & / & \\
\hline Apero \& Appetizers & 0,53 & 0,01 & 0,55 & 0,01 & $-1,21(0,33)$ & $0,08(0,33)$ & $0,20(0,34)$ & $0,37(0,52)$ & $0,71(0,44)$ & \\
\hline Vegetarian products, chilled & 0,42 & 0,00 & 0,42 & 0,00 & $-1,07(0,27)$ & $1,02(0,21)$ & $0,05(0,21)$ & $-0,02(0,10)$ & l & $A->B$ \\
\hline World food & 0,34 & 0,00 & 0,37 & 0,00 & $-0,27(0,17)$ & $0,30(0,24)$ & $0,39(0,25)$ & $0,52(0,21)$ & $-0,94(0,18)$ & \\
\hline Flour and dessert preparations & 0,31 & 0,00 & 0,28 & 0,00 & $0,35(0,25)$ & $-0,66(0,19)$ & $0,48(0,27)$ & $-0,29(0,28)$ & $0,11(0,25)$ & \\
\hline
\end{tabular}


for the following food categories: ice-cream and frozen desserts, bread, sugar and sweeteners, Apero Corner, chilled (cheese, salami, humus, olives etc.), and chilled vegetarian products. The opposite was found for: processed meat, hot drinks, cakes and pastries, and frozen vegetables and soups (Table 5).

The mean change in the proportion of total food sales for Nutri-Score D products from before to after was lower $(p<0.0008)$ for intervention than control stores for the following food categories: canned prepared ambient meals. The opposite was found for milk and plant based drinks, ambient fresh fruit juices, meals to go, frozen pizzas and prepared meals, and Apero Corner, chilled (cheese, salami, humus, olives etc.).

The mean change in the proportion of total food sales for Nutri-Score E products from before to after was lower $(p<0.0008)$ for intervention than control stores for the following food categories: cheeses, yoghurts soft white cheeses and desserts, juices fresh chilled, and world food. The opposite was found for: bread preparations, and Apero Corner, chilled (cheese, salami, humus, olives etc.) (Table 5).

\section{Discussion}

This is the first study generating real world evidence of the impact of electronic shelf labels on all food products in-store on consumer food purchases. It was found that, overall, comparing pre- and post-intervention periods, difference-in-differences for the proportion of NutriScore $B$ and $C$ product sales were more favourable in intervention than control stores, while difference-indifferences for the proportion of Nutri-Score D product sales were less favourable in intervention than control stores. Across the 58 food categories investigated in the study, taking into account either significant changes in proportion of sales within food categories or significant changes in proportion of total sales for healthier (NutriScore A, B) and less healthy (Nutri-Score D, E) food products, no significant impact was found for 20/58 food categories, while for 17/58 food categories (representing about $29 \%$ of total food sales) a significant positive impact (either increase in healthier and/or decrease in less healthy food sales) was found. For 16/58 of food categories (representing $24 \%$ of total food sales) a significant negative impact (either decrease in healthier and/or increase in less healthy food sales) was found and for 5 food categories the impact was mixed. Positive impacts were found in particular for the groups of vegetables (i.e. fresh ready-to-use vegetables, frozen French fries and potato products and frozen vegetables and soups), fruits (fresh fruit, dried fruit including nuts), dairy products (cheeses, yoghurt soft white cheeses and desserts), and sugar and confectionery. Negative impacts were mainly found for the group of bread and bakery products.

Most previous studies used a simulated shopping situation to assess the impact of FOP or shelf labeling initiatives. A recent review reported that shoppers exposed to FOP or shelf labels had an increased intent to purchase healthier foods, such that FOP labels or shelf labels taken as a whole may achieve a small degree of success at persuading shoppers to buy healthier foods $(<2.0 \%$ shift in healthiness of food purchases) [13]. Studies carried out in real-world supermarkets, such as the present study, generate results that have more credibility than do studies in a simulated shopping situation as shoppers are not part of an experiment (which may influence their purchases) and they have more time to adapt to the intervention. Only a few studies have been conducted in real-world supermarkets. They used different types of shelf labeling schemes and found mixed results. Nutrient-specific systems like the traffic lights or sugar labels did not show an impact on purchases, while summary indicator systems like the Guiding Stars or NuVal did show an increase in sales of healthier foods. For example, a chain of supermarkets in the UK introduced Multiple Traffic Lights (MTL) on ready meals and sandwiches but revealed no shift to healthier products after 1 month's time [14]. A similar study with MTL was carried out in an online supermarket in Australia [15], but there was no evidence that the FOP labels led to an increase in sales of healthier foods after 10 weeks. A recent study from the Netherlands evaluated the effectiveness of an industry-designed on-shelf sugar label on the sales of beverages with no, low, medium and high sugar content implemented within a realworld supermarket [16]. The study found that this label did not significantly decrease unhealthy beverage sales or significantly increase healthier beverage sales [16]. Two studies were carried out with Guiding stars attached to the shelves adjacent to the foods in supermarket chains in Canada and the USA. The Canadian study included a wide variety of foods [17]. Over the course of 6 months, relative to control supermarkets, shoppers in intervention supermarkets made small but significant shifts toward purchasing foods with higher nutritional ratings; however, shifts varied in direction and magnitude across food categories.

The other study was conducted in the USA and focused on the sales of ready-to-eat cereals [18]. Over the course of 7 months, sales of cereals with no stars fell by $2.6 \%$ (comparing stores carrying the logo with control stores) while sales of cereals with one, two, and three stars increased by $1.15,0.89$, and $0.54 \%$, respectively. Another study in the US using the NuVAL 
Table 5 Difference-in-difference coefficients for proportion of total food sales for Nutri-Score A, B, C,D, E products by food category adjusted for region, cluster, total non-food sales and week of the year

\begin{tabular}{|c|c|c|c|c|c|c|c|c|c|c|}
\hline \multirow{3}{*}{ Broad food category } & \multicolumn{10}{|c|}{$\%$ diff in diff for proportion of total food sales } \\
\hline & \multicolumn{2}{|c|}{ A } & \multicolumn{2}{|c|}{ B } & \multicolumn{2}{|c|}{ c } & \multicolumn{2}{|c|}{ D } & \multicolumn{2}{|c|}{ E } \\
\hline & diff & SE & diff & SE & diff & SE & diff & SE & diff & SE \\
\hline Meat, fish, eggs and related products & & & & & & & & & & \\
\hline Fresh packaged meat & 0,00627 & 0,00615 & 0,00087 & 0,00367 & 0,00016 & 0,00318 & 0,00067 & 0,00379 & 0,00021 & 0,00031 \\
\hline Processed meat (charcuterie) & 0,00056 & 0,00028 & $-0,01004$ & 0,00090 & 0,00701 & 0,00276 & $-0,00431$ & 0,00243 & $-0,00694$ & 0,00280 \\
\hline Poultry, rabbit and exotic meat & 0,00791 & 0,00419 & $-0,00369$ & 0,00164 & $-0,00583$ & 0,00180 & $-0,00199$ & 0,00064 & $-0,00002$ & 0,00015 \\
\hline Fresh fish & $-0,01252$ & 0,00443 & $-0,00102$ & 0,00087 & $-0,00178$ & 0,00065 & $-0,00074$ & 0,00117 & / & / \\
\hline Processed fish & / & / & $-0,00036$ & 0,00049 & $-0,00018$ & 0,00034 & 0,00632 & 0,00274 & $-0,00017$ & 0,00006 \\
\hline Shrimps & $-0,00051$ & 0,00016 & $-0,00037$ & 0,00111 & $-0,00685$ & 0,00351 & $-0,00010$ & 0,00014 & I & I \\
\hline Frozen meat, fish, crustaceans & $-0,00043$ & 0,00170 & 0,00096 & 0,00071 & 0,00070 & 0,00029 & 0,00106 & 0,00038 & 0,00034 & 0,00013 \\
\hline Eggs and egg products & $-0,00014$ & 0,00065 & 0,00237 & 0,00121 & I & I & 0,00022 & 0,00009 & I & I \\
\hline Canned fish and meat & 0,00073 & 0,00057 & $-0,00087$ & 0,00119 & 0,00070 & 0,00045 & $-0,00016$ & 0,00108 & 0,00008 & 0,00014 \\
\hline Fresh crustaceans and mollusks & $-0,00377$ & 0,00290 & $-0,00345$ & 0,00353 & $-0,00084$ & 0,00096 & 0,00015 & 0,00017 & $-0,00006$ & 0,00012 \\
\hline Game & $-0,00251$ & 0,00483 & 0,00070 & 0,00067 & 0,00140 & 0,00045 & $-0,00049$ & 0,00024 & / & / \\
\hline Marinated fish and shellfish & 0,00012 & 0,00007 & $-0,00008$ & 0,00008 & 0,00039 & 0,00026 & $-0,00079$ & 0,00069 & / & / \\
\hline Cheeses and dairy products & & & & & & & & & & \\
\hline Cheeses & $-0,00013$ & 0,00015 & I & I & 0,00039 & 0,00090 & 0,00959 & 0,00402 & $-0,00270$ & 0,00064 \\
\hline Yoghurt, soft white cheese and desserts & 0,00143 & 0,00097 & $-0,00052$ & 0,00152 & $-0,00197$ & 0,00149 & 0,00198 & 0,00070 & $-0,00181$ & 0,00044 \\
\hline Milk UHT / fresh and plant-based drinks & 0,00037 & 0,00074 & $-0,00136$ & 0,00149 & 0,00076 & 0,00034 & 0,00073 & 0,00016 & / & / \\
\hline Ice-cream and frozen desserts & $-0,00092$ & 0,00027 & 0,00261 & 0,00046 & 0,00270 & 0,00083 & 0,00533 & 0,00212 & 0,00129 & 0,00052 \\
\hline Ingredients dairy & $-0,00367$ & 0,00176 & 0,00015 & 0,00018 & $-0,00257$ & 0,00067 & 0,00117 & 0,00095 & $-0,00049$ & 0,00016 \\
\hline Beverages & & & & & & & & & & \\
\hline Soft drinks (light, zero, regular) & $-0,00015$ & 0,00007 & 0,00456 & 0,01168 & $-0,00519$ & 0,00083 & 0,00838 & 0,00528 & 0,00773 & 0,00633 \\
\hline Waters (including flavoured) & 0,00007 & 0,00307 & $-0,00127$ & 0,00077 & / & / & $-0,00107$ & 0,00038 & $-0,00032$ & 0,00021 \\
\hline Fruit juices, ambient & $-0,00143$ & 0,00032 & $-0,00002$ & 0,00014 & 0,00385 & 0,00075 & 0,00076 & 0,00020 & 0,00036 & 0,00044 \\
\hline Juices, fresh, chilled & / & I & $-0,00006$ & 0,00015 & $-0,00270$ & 0,00145 & $-0,00034$ & 0,00026 & $-0,00096$ & 0,00018 \\
\hline $\begin{array}{l}\text { Non-alcoholic drinks } \\
\text { Bread and bakery products }\end{array}$ & I & I & 0,00003 & 0,00049 & 0,00003 & 0,00008 & 0,00038 & 0,00036 & 0,00035 & 0,00041 \\
\hline Bread & $-0,02371$ & 0,00352 & 0,02440 & 0,00390 & $-0,00419$ & 0,00138 & $-0,00226$ & 0,00159 & $-0,00003$ & 0,00016 \\
\hline Sweet biscuits & $-0,00027$ & 0,00006 & $-0,00025$ & 0,00013 & 0,21030 & 0,12965 & $-0,00197$ & 0,00099 & 0,00023 & 0,00200 \\
\hline Cakes and pastries & / & / & $-0,00335$ & 0,00030 & $-0,00450$ & 0,00135 & $-0,00341$ & 0,00178 & 0,00699 & 0,00342 \\
\hline Viennese cakes and buns & I & I & I & I & 0,00029 & 0,00014 & $-0,00155$ & 0,00088 & 0,00036 & 0,00063 \\
\hline Bread preparations (i.e. crackers, rusks) & 0,00020 & 0,00017 & 0,00022 & 0,00015 & 0,00081 & 0,00026 & 0,00048 & 0,00017 & 0,00062 & 0,00014 \\
\hline Grains and cereals & & & & & & & & & & \\
\hline Pasta, rice and starch products & 0,00286 & 0,00158 & 0,00044 & 0,00035 & 0,00006 & 0,00027 & 0,00020 & 0,00012 & / & / \\
\hline Breakfast cereals & $-0,00003$ & 0,00047 & $-0,00073$ & 0,00028 & 0,00051 & 0,00067 & 0,00060 & 0,00050 & 0,00048 & 0,00021 \\
\hline Prepared and convenience meals & & & & & & & & & & \\
\hline$\overline{\text { Meals to cook and heat (i.e. lasagna, goulash) }}$ & $-0,00019$ & 0,00149 & $-0,00101$ & 0,00162 & 0,00049 & 0,00146 & $-0,00022$ & 0,00138 & $-0,00034$ & 0,00012 \\
\hline Meals to go (i.e. wraps, salads, sandwiches) & $-0,00101$ & 0,00127 & $-0,00294$ & 0,00132 & $-0,00210$ & 0,00093 & 0,00070 & 0,00011 & $-0,00040$ & 0,00012 \\
\hline Frozen pizzas and prepared meals & 0,00037 & 0,00022 & $-0,00044$ & 0,00060 & 0,00021 & 0,00077 & 0,00422 & 0,00075 & 0,00004 & 0,00010 \\
\hline Meals to compose & $-0,00002$ & 0,00026 & $-0,00005$ & 0,00068 & $-0,00582$ & 0,00060 & $-0,00024$ & 0,00009 & / & / \\
\hline Meals concept \& event & / & / & $-0,00072$ & 0,00016 & $-0,00348$ & 0,00081 & 0,00172 & 0,00030 & / & / \\
\hline Prepared meals canned ambient & $-0,00043$ & 0,00026 & $-0,00075$ & 0,00026 & 0,00061 & 0,00015 & $-0,00110$ & 0,00021 & / & / \\
\hline Chocolate, sugar and confectionery & & & & & & & & & & \\
\hline Chocolate, including bars & / & / & / & / & 0,00020 & 0,00027 & 0,00128 & 0,00051 & 0,00017 & 0,00395 \\
\hline Sweet bread toppings (chocolate, jam, honey, pinda) & 0,00019 & 0,00013 & 0,00031 & 0,00014 & 0,00200 & 0,00046 & 0,00210 & 0,00086 & $-0,00041$ & 0,00057 \\
\hline Confectionery & 0,00035 & 0,00011 & 0,00018 & 0,00300 & 0,00057 & 0,00028 & $-0,00518$ & 0,00405 & 0,00130 & 0,00083 \\
\hline Sugar and sweeteners & / & / & 0,00072 & 0,00018 & 0,00011 & 0,00016 & $-0,00073$ & 0,00053 & 0,00138 & 0,00158 \\
\hline Syrups & / & / & 0,00040 & 0,00011 & 0,00095 & 0,00044 & 0,00008 & 0,00012 & $-0,00054$ & 0,00068 \\
\hline Fats and oils & & & & & & & & & & \\
\hline$\overline{\text { Spreadable fats (i.e. butter, margarines) }}$ & / & / & / & / & $-0,00296$ & 0,00052 & 0,00178 & 0,00087 & 0,00224 & 0,00109 \\
\hline Oil and vinegar & $-0,00019$ & 0,00048 & $-0,00006$ & 0,00004 & 0,00079 & 0,00044 & $-0,00211$ & 0,00204 & 0,00036 & 0,00014 \\
\hline Savoury snacks & & & & & & & & & & \\
\hline Aperitif snacks (i.e. chips, salted biscuits) & $-0,00133$ & 0,00026 & $-0,00044$ & 0,00016 & 0,00029 & 0,00109 & 0,00018 & 0,00123 & $-0,00028$ & 0,00042 \\
\hline Condiments, soups and sauces & & & & & & & & & & \\
\hline Condiments and sauces & 0,00020 & 0,00036 & 0,00057 & 0,00031 & $-0,00044$ & 0,00071 & 0,00060 & 0,00126 & $-0,00051$ & 0,00041 \\
\hline Soups, canned & 0,00020 & 0,00012 & $-0,00042$ & 0,00057 & $-0,00017$ & 0,00057 & $-0,00024$ & 0,00008 & 0,00023 & 0,00009 \\
\hline$\underline{\text { Veqetables }}$ & & & & & & & & & & \\
\hline Ready-to-use fresh vegetables, including potatoes & 0,00248 & 0,00144 & $-0,00061$ & 0,00016 & $-0,00025$ & 0,00010 & $-0,00010$ & 0,00005 & / & / \\
\hline Canned vegetables & 0,00179 & 0,00131 & 0,00013 & 0,00013 & 0,00016 & 0,00010 & / & / & / & / \\
\hline Frozen French fries and potato products & 0,00293 & 0,00056 & 0,00047 & 0,00071 & $-0,00029$ & 0,00028 & 0,00047 & 0,00025 & / & / \\
\hline Frozen vegetables and soups & 0,00313 & 0,00076 & $-0,00098$ & 0,00025 & 0,00030 & 0,00018 & / & / & 0,00019 & 0,00007 \\
\hline Fruits & & & & & & & & & & \\
\hline$\overline{\text { Fresh fruit }}$ & 0,01013 & 0,00835 & 0,00012 & 0,00008 & $-0,00081$ & 0,00013 & / & / & / & / \\
\hline Dried fruit (including nuts) & $-0,00138$ & 0,00070 & 0,00397 & 0,00146 & $-0,00171$ & 0,00052 & 0,00084 & 0,00027 & $-0,00001$ & 0,00003 \\
\hline Canned fruit & $-0,00072$ & 0,00071 & 0,00098 & 0,00029 & $-0,00032$ & 0,00024 & 0,00013 & 0,00011 & 1 & / \\
\hline Miscellaneous & & & & & & & & & & \\
\hline Apero Corner, chilled (cheese, salami, humus, olives etc & 0,00624 & 0,00076 & 0,00142 & 0,00042 & 0,00586 & 0,00085 & 0,01052 & 0,00092 & 0,00278 & 0,00063 \\
\hline Spreadable salads (i.e. meat, crab, etc.) & / & / & $-0,00054$ & 0,00023 & 0,00059 & 0,00043 & $-0,00200$ & 0,00073 & / & I \\
\hline Apero \& Appetizers & $-0,00051$ & 0,00067 & 0,00128 & 0,00054 & 0,00000 & 0,00072 & 0,00274 & 0,00159 & 0,00275 & 0,00215 \\
\hline Vegetarian products, chilled & 0,00043 & 0,00060 & 0,00209 & 0,00031 & 0,00116 & 0,00034 & 0,00011 & 0,00012 & / & / \\
\hline World food & $-0,00006$ & 0,00020 & 0,00053 & 0,00027 & 0,00069 & 0,00034 & 0,00091 & 0,00030 & $-0,00072$ & 0,00018 \\
\hline Flour and dessert preparations & 0,00022 & 0,00025 & $-0,00040$ & 0,00020 & $-0,00004$ & 0,00028 & $-0,00079$ & 0,00034 & $-0,00015$ & 0,00025 \\
\hline
\end{tabular}


shelf nutrition label, showed that after the change in the nutrient profile model underpinning the NuVAL (whereby average NuVAL scores decreased), yogurt sales declined. A 1-point increase in the NuVal score was estimated to increase sales of the corresponding yogurt product by $0.49 \%$ [19]. In the present study, the Nutri-Score, which is also a summary indicator system, was used as the shelf nutrition label. We found mixed results, dependent on the food categories and the Nutri-Score category studied. Our study is the first retailer-initiated natural experiment using Nutri-Score shelf labeling for all food products in-store. The impact of the ESL was investigated over and above other NutriScore related actions taken by the retailer. This could explain why the impact of the ESL intervention was not as consistent as that observed in previous studies using other summary indicator systems such as NuVal or Guiding Stars.

Shelf labeling interventions may not be able to overcome consumers' strong preferences for particular foods and brands, and in-store displays and promotions may further reduce the effect of these interventions. Combining shelf labeling interventions with other nudges, such as price incentives or reductions in promotions for less healthy foods, are likely to be more effective [20]. It is important to note that the potential effect of the shelf labeling intervention, as measured in this study, may be lower than anticipated, due to the fact that other actions related to Nutri-Score (i.e. education and social marketing, voluntary front-of-pack labeling, price promotions on products with NutriScore A and B) were also in place over the course of the study.

While each of these particular actions could influence food purchases, they are unlikely to confound the effect of the ESL intervention because Delhaize displayed the Nutri-Score on-pack for new products in all stores at the same time and all other aforementioned Nutri-Score related actions took place at the same time across all Delhaize stores.

In addition, the ESL is in black and white, rather than in colour, such as with the Nutri-Score FOP. Previous studies found that Nutri-Score, with a summarized graded and color-coded format, using semantic colours, is associated to a higher objective understanding than monochrome and nutrient-specific labels [21]. The presence of colour in MTL and Nutri-Score labels is probably an additional reason for their effectiveness [22]. Although this has not been tested, the shelf labels, found on all products in store, could be an incentive for food companies to put Nutri-Score on their food packages and hence further stimulate reformulation efforts as well as increase impacts for the consumer.
There is no data on the potential population health impact of the intervention assessed in this study. A recent French study estimated that approximately $3.4 \%$ of all deaths from diet-related non-communicable diseases were avoidable due to implementation of the Nutri-Score FOP label on food packages in France [23].

Strengths of this study include the use of sales data for a comprehensive set of food groups and the use of a controlled design. Limitations include the reliance on retailer-defined food categories, the absence of available data on units and weights sold and the limited intervention period (longer period of follow-up not possible due to changes in purchase behaviour caused by the COVID-19 pandemic). Another limitation is that some intervention stores for which a control store could not be assigned were not included in the study.

There was no data available on in-store availability (for example the shelf-space allocation) for foods from each Nutri-Score category for the control and intervention stores. However, the retailer confirmed there were no interventions impacting availability of food products during the duration of the study and since we had matched control and intervention stores with respect to store characteristics the range of products available was likely similar.

In addition, even with a controlled design, it is possible that some other Nutri-Score related actions (i.e. FOP label, promotions, consumer social marketing) had differential effects in different shops, or with different populations, which this study may not have fully accounted for.

In conclusion, the impact of ESL with Nutri-Score on consumer purchases was mixed. Favourable difference-in-differences were found for Nutri-Score B and $C$ products and unfavourable difference-in-differences for Nutri-Score D products. Shelf labeling on its own is unlikely to significantly influence consumer behaviours and should be supplemented with additional actions targeting marketing and prices.

\section{Appendix 1}

Table 6

Table 6 Implementation of Nutri-Score on ESL across the different Delhaize stores in Belgium

\begin{tabular}{ll}
\hline ESL implementation & N Stores \\
\hline ESL not possible & 11 \\
May 2019 & 8 \\
June 2019 & 104 \\
September 2019 & 3 \\
October 2019 & 2 \\
Total & $\mathbf{1 2 8}$ \\
\hline
\end{tabular}




\section{Appendix 2}

\section{Table 7}

Table 7 Food categories and their average \% contributions to total food sales for control and intervention stores

\begin{tabular}{|c|c|c|c|c|}
\hline \multirow[t]{2}{*}{ Food category } & \multicolumn{2}{|c|}{ Control stores } & \multicolumn{2}{|c|}{ Intervention stores } \\
\hline & Mean & stderr & mean & stderr \\
\hline Fresh packaged meat & 8,799 & 0,050 & 8,746 & 0,027 \\
\hline Fresh fruit & 7,834 & 0,046 & 8,205 & 0,028 \\
\hline Cheeses & 6,393 & 0,026 & 6,328 & 0,013 \\
\hline Processed meat (charcuterie) & 5,544 & 0,027 & 5,426 & 0,014 \\
\hline Soft drinks (light, zero, regular) & 4,927 & 0,033 & 4,826 & 0,025 \\
\hline Bread & 4,051 & 0,025 & 4,051 & 0,012 \\
\hline Poultry, rabbit and exotic meat & 3,656 & 0,021 & 3,586 & 0,011 \\
\hline Yoghurt, soft white cheese and desserts & 3,575 & 0,019 & 3,604 & 0,009 \\
\hline Fresh fish & 3,451 & 0,022 & 3,374 & 0,012 \\
\hline Waters (including flavoured) & 2,695 & 0,018 & 2,719 & 0,009 \\
\hline Meals to cook and heat (i.e. lasagna, goulash) & 2,435 & 0,016 & 2,315 & 0,007 \\
\hline Sweet biscuits & 2,263 & 0,079 & 2,161 & 0,006 \\
\hline Cakes and pastries & 2,028 & 0,019 & 2,011 & 0,008 \\
\hline Chocolate, including bars & 1,897 & 0,017 & 1,844 & 0,009 \\
\hline Spreadable fats (i.e. butter, margarines) & 1,748 & 0,007 & 1,663 & 0,004 \\
\hline Aperitif snacks (i.e. chips, salted biscuits) & 1,677 & 0,008 & 1,639 & 0,004 \\
\hline Milk UHT / fresh and plant-based drinks & 1,495 & 0,011 & 1,512 & 0,006 \\
\hline Ice-cream and frozen desserts & 1,375 & 0,019 & 1,409 & 0,011 \\
\hline Condiments and sauces & 1,367 & 0,008 & 1,312 & 0,004 \\
\hline Ready-to-use fresh vegetables, including potatoes & 1,268 & 0,007 & 1,276 & 0,003 \\
\hline Processed fish & 1,237 & 0,012 & 1,252 & 0,006 \\
\hline Meals to go (i.e. wraps, salads, sandwiches) & 1,193 & 0,014 & 1,242 & 0,007 \\
\hline Pasta, rice and starch products & 1,121 & 0,007 & 1,114 & 0,004 \\
\hline Shrimps & 1,093 & 0,016 & 1,098 & 0,009 \\
\hline Ingredients dairy & 1,078 & 0,006 & 1,055 & 0,003 \\
\hline Canned vegetables & 0,985 & 0,005 & 0,947 & 0,003 \\
\hline Sweet bread toppings (chocolate, jam, honey, pinda) & 0,943 & 0,005 & 0,926 & 0,003 \\
\hline Frozen meat, fish, crustaceans & 0,926 & 0,008 & 0,903 & 0,004 \\
\hline Frozen pizzas and prepared meals & 0,886 & 0,007 & 0,876 & 0,003 \\
\hline Confectionery & 0,857 & 0,006 & 0,799 & 0,006 \\
\hline Eggs and egg products & 0,828 & 0,003 & 0,880 & 0,003 \\
\hline Dried fruit (including nuts) & 0,786 & 0,006 & 0,869 & 0,004 \\
\hline Canned fish and meat & 0,764 & 0,008 & 0,749 & 0,004 \\
\hline Breakfast cereals & 0,764 & 0,005 & 0,814 & 0,003 \\
\hline Oil and vinegar & 0,734 & 0,007 & 0,716 & 0,003 \\
\hline Apero Corner, chilled (cheese, salami, humus, olives etc.) & 0,733 & 0,010 & 0,840 & 0,007 \\
\hline Spreadable salads (i.e. meat, crab, etc.) & 0,671 & 0,004 & 0,651 & 0,002 \\
\hline Fresh crustaceans and mollusks & 0,657 & 0,017 & 0,664 & 0,009 \\
\hline Fruit juices, ambient & 0,627 & 0,003 & 0,641 & 0,002 \\
\hline Frozen French fries and potato products & 0,617 & 0,004 & 0,585 & 0,002 \\
\hline Frozen vegetables and soups & 0,591 & 0,005 & 0,569 & 0,002 \\
\hline Juices, fresh, chilled & 0,553 & 0,005 & 0,668 & 0,004 \\
\hline Apero \& Appetizers & 0,525 & 0,013 & 0,552 & 0,007 \\
\hline Viennese cakes and buns & 0,516 & 0,005 & 0,551 & 0,003 \\
\hline Soups, canned & 0,448 & 0,004 & 0,408 & 0,002 \\
\hline Canned fruit & 0,429 & 0,003 & 0,388 & 0,001 \\
\hline
\end{tabular}


Table 7 (continued)

\begin{tabular}{|c|c|c|c|c|}
\hline \multirow[t]{2}{*}{ Food category } & \multicolumn{2}{|c|}{ Control stores } & \multicolumn{2}{|c|}{ Intervention stores } \\
\hline & Mean & stderr & mean & stderr \\
\hline Vegetarian products, chilled & 0,415 & 0,003 & 0,419 & 0,002 \\
\hline Meals to compose & 0,382 & 0,004 & 0,410 & 0,002 \\
\hline Game & 0,371 & 0,017 & 0,423 & 0,011 \\
\hline World food & 0,340 & 0,003 & 0,370 & 0,002 \\
\hline Meals concept \& event & 0,330 & 0,003 & 0,380 & 0,003 \\
\hline Flour and dessert preparations & 0,312 & 0,003 & 0,281 & 0,001 \\
\hline Sugar and sweeteners & 0,303 & 0,002 & 0,296 & 0,001 \\
\hline Bread preparations (i.e. crackers, rusks) & 0,259 & 0,002 & 0,245 & 0,001 \\
\hline Syrups & 0,231 & 0,004 & 0,214 & 0,002 \\
\hline Marinated fish and shellfish & 0,193 & 0,002 & 0,181 & 0,001 \\
\hline Prepared meals canned ambient & 0,154 & 0,002 & 0,133 & 0,001 \\
\hline Non-alcoholic drinks & 0,092 & 0,002 & 0,088 & 0,001 \\
\hline
\end{tabular}




\section{Appendix 3}

Table 8

Table 8 Impact of ESL on proportion of weekly sales for Nutri-Score A, B, C, D, E products by food category, unadjusted and adjusted for region, cluster, week and non-food sales

\begin{tabular}{|c|c|c|c|c|c|c|c|c|c|c|}
\hline \multirow[t]{2}{*}{ Food category } & \multirow[t]{2}{*}{ Nutri-Score } & \multicolumn{3}{|c|}{ Unadjusted } & \multicolumn{3}{|c|}{$\begin{array}{l}\text { Adjusted for region, } \\
\text { cluster, non-food sales }\end{array}$} & \multicolumn{3}{|c|}{$\begin{array}{l}\text { Adjusted for region, } \\
\text { cluster, non-food sales, } \\
\text { week of the year }\end{array}$} \\
\hline & & Estimate & StdErr & $p$ & Estimate & StdErr & $p$ & Estimate & StdErr & $p$ \\
\hline Frozen meat, fish, crustaceans & A & -0.4751 & 0.5094 & 0.3511 & -0.8723 & 0.4960 & 0.0787 & -0.5587 & 0.2943 & 0.0577 \\
\hline Frozen meat, fish, crustaceans & B & 0.0773 & 0.4464 & 0.8626 & 0.4705 & 0.4327 & 0.2769 & 0.0781 & 0.2331 & 0.7376 \\
\hline Frozen meat, fish, crustaceans & $C$ & 0.1950 & 0.1437 & 0.1749 & 0.2844 & 0.1415 & 0.0445 & 0.2054 & 0.1135 & 0.0705 \\
\hline Frozen meat, fish, crustaceans & $\mathrm{D}$ & 0.0812 & 0.1869 & 0.6640 & 0.0625 & 0.1871 & 0.7383 & 0.1570 & 0.1479 & 0.2882 \\
\hline Frozen meat, fish, crustaceans & $E$ & 0.0802 & 0.0683 & 0.2405 & 0.0429 & 0.0674 & 0.5249 & 0.1253 & 0.0509 & 0.0138 \\
\hline Canned Fish and meat & A & 0.7483 & 0.2358 & 0.0015 & 0.7485 & 0.2360 & 0.0015 & 0.7102 & 0.1954 & 0.0003 \\
\hline Canned Fish and meat & B & -0.6022 & 0.4096 & 0.1416 & -0.5315 & 0.4095 & 0.1944 & -0.7441 & 0.3175 & 0.0191 \\
\hline Canned Fish and meat & C & 0.1958 & 0.2276 & 0.3897 & 0.2516 & 0.2275 & 0.2689 & 0.1398 & 0.1832 & 0.4454 \\
\hline Canned Fish and meat & $\mathrm{D}$ & -0.3492 & 0.4203 & 0.4062 & -0.3922 & 0.4207 & 0.3513 & -0.1611 & 0.3130 & 0.6067 \\
\hline Canned Fish and meat & E & 0.0194 & 0.1037 & 0.8513 & -0.0417 & 0.1021 & 0.6828 & 0.0560 & 0.0749 & 0.4545 \\
\hline Fresh packaged meat & A & 0.2543 & 0.3044 & 0.4035 & 0.3969 & 0.3015 & 0.1881 & 0.4128 & 0.1699 & 0.0152 \\
\hline Fresh packaged meat & B & 0.0168 & 0.2120 & 0.9367 & -0.0185 & 0.2120 & 0.9305 & -0.0113 & 0.1358 & 0.9335 \\
\hline Fresh packaged meat & C & 0.0834 & 0.1596 & 0.6012 & 0.0719 & 0.1597 & 0.6526 & 0.0006 & 0.1292 & 0.9965 \\
\hline Fresh packaged meat & $\mathrm{D}$ & -0.3569 & 0.2688 & 0.1845 & -0.4453 & 0.2678 & 0.0964 & -0.4030 & 0.1543 & 0.0090 \\
\hline Fresh packaged meat & $E$ & 0.0025 & 0.0178 & 0.8880 & -0.0076 & 0.0176 & 0.6661 & -0.0000 & 0.0164 & 0.9988 \\
\hline Processed meat (charcuterie) & A & 0.0089 & 0.0258 & 0.7307 & 0.0118 & 0.0259 & 0.6472 & 0.0279 & 0.0178 & 0.1164 \\
\hline Processed meat (charcuterie) & B & -0.5033 & 0.1261 & $<.0001$ & -0.5477 & 0.1256 & $<.0001$ & -0.5636 & 0.0574 & $<.0001$ \\
\hline Processed meat (charcuterie) & C & 0.6461 & 0.3227 & 0.0453 & 0.5539 & 0.3214 & 0.0848 & 0.7305 & 0.1483 & $<.0001$ \\
\hline Processed meat (charcuterie) & $\mathrm{D}$ & -0.0706 & 0.2829 & 0.8029 & 0.1918 & 0.2730 & 0.4823 & -0.0734 & 0.1425 & 0.6064 \\
\hline Processed meat (charcuterie) & $E$ & -0.0617 & 0.2394 & 0.7966 & -0.1657 & 0.2378 & 0.4860 & -0.0907 & 0.1486 & 0.5416 \\
\hline Poultry, rabbit and exotic & A & 1,1798 & 0.5248 & 0.0246 & 1,3083 & 0.5242 & 0.0126 & 1,3015 & 0.2245 & $<.0001$ \\
\hline Poultry, rabbit and exotic & B & -0.2504 & 0.3559 & 0.4818 & -0.3256 & 0.3556 & 0.3599 & -0.3319 & 0.1586 & 0.0364 \\
\hline Poultry, rabbit and exotic & C & -0.6714 & 0.3639 & 0.0651 & -0.6562 & 0.3642 & 0.0717 & -0.7567 & 0.1658 & $<.0001$ \\
\hline Poultry, rabbit and exotic & $\mathrm{D}$ & -0.2615 & 0.1060 & 0.0136 & -0.3182 & 0.1047 & 0.0024 & -0.2191 & 0.0671 & 0.0011 \\
\hline Poultry, rabbit and exotic & $E$ & -0.0016 & 0.0230 & 0.9406 & -0.0069 & 0.0219 & 0.7529 & 0.0005 & 0.0179 & 0.9772 \\
\hline Game & A & -0.7642 & 1,2069 & 0.5267 & $-1,1234$ & 1,1990 & 0.3490 & $-1,2000$ & 0.9991 & 0.2299 \\
\hline Game & B & 0.0099 & 0.9684 & 0.9919 & 0.4846 & 0.9340 & 0.6040 & 0.3292 & 0.8514 & 0.6991 \\
\hline Game & C & 3,1733 & 1,7959 & 0.0775 & 4,1104 & 1,7707 & 0.0204 & 2,9877 & 1,1456 & 0.0092 \\
\hline Game & $\mathrm{D}$ & $-1,9164$ & 2,1397 & 0.3707 & $-1,7999$ & 2,1614 & 0.4052 & -0.8218 & 0.7344 & 0.2634 \\
\hline Fresh fish & A & -0.1584 & 0.3281 & 0.6293 & -0.0945 & 0.3279 & 0.7731 & -0.1008 & 0.1820 & 0.5796 \\
\hline Fresh fish & $\mathrm{B}$ & 0.1228 & 0.1390 & 0.3770 & 0.0244 & 0.1360 & 0.8574 & 0.1207 & 0.0981 & 0.2189 \\
\hline Fresh fish & C & -0.0978 & 0.1204 & 0.4166 & -0.1660 & 0.1187 & 0.1621 & -0.0911 & 0.0761 & 0.2316 \\
\hline Fresh fish & $\mathrm{D}$ & 0.1275 & 0.2314 & 0.5816 & 0.2251 & 0.2295 & 0.3266 & 0.0695 & 0.1213 & 0.5667 \\
\hline Fresh crustaceans and mollusks & A & $-1,4266$ & 0.9833 & 0.1469 & $-1,3748$ & 0.9847 & 0.1627 & $-1,2014$ & 0.5575 & 0.0312 \\
\hline Fresh crustaceans and mollusks & B & 1,8213 & 1,3615 & 0.1811 & 1,5804 & 1,3613 & 0.2457 & 1,3125 & 0.5751 & 0.0225 \\
\hline Fresh crustaceans and mollusks & C & 0.5650 & 0.7529 & 0.4531 & 0.8894 & 0.7468 & 0.2338 & 0.5486 & 0.4794 & 0.2525 \\
\hline Fresh crustaceans and mollusks & $\mathrm{D}$ & -0.2009 & 0.1074 & 0.0616 & -0.1687 & 0.1072 & 0.1156 & -0.1341 & 0.0945 & 0.1559 \\
\hline Fresh crustaceans and mollusks & $E$ & 0.0592 & 0.0469 & 0.2072 & 0.0719 & 0.0467 & 0.1233 & 0.0241 & 0.0408 & 0.5541 \\
\hline Processed fish & B & 0.0226 & 0.1465 & 0.8773 & 0.0769 & 0.1461 & 0.5986 & -0.0209 & 0.1244 & 0.8667 \\
\hline Processed fish & C & -0.0367 & 0.1262 & 0.7714 & 0.0138 & 0.1256 & 0.9125 & -0.0875 & 0.1017 & 0.3901 \\
\hline Processed fish & $\mathrm{D}$ & 0.0349 & 0.2074 & 0.8665 & -0.0542 & 0.2062 & 0.7928 & 0.1484 & 0.1633 & 0.3634 \\
\hline Processed fish & $E$ & -0.0441 & 0.0222 & 0.0468 & -0.0335 & 0.0218 & 0.1248 & -0.0409 & 0.0208 & 0.0493 \\
\hline
\end{tabular}


Table 8 (continued)

\begin{tabular}{|c|c|c|c|c|c|c|c|c|c|c|}
\hline \multirow[t]{2}{*}{ Food category } & \multirow[t]{2}{*}{ Nutri-Score } & \multicolumn{3}{|c|}{ Unadjusted } & \multicolumn{3}{|c|}{$\begin{array}{l}\text { Adjusted for region, } \\
\text { cluster, non-food sales }\end{array}$} & \multicolumn{3}{|c|}{$\begin{array}{l}\text { Adjusted for region, } \\
\text { cluster, non-food sales, } \\
\text { week of the year }\end{array}$} \\
\hline & & Estimate & StdErr & $p$ & Estimate & StdErr & $p$ & Estimate & StdErr & $p$ \\
\hline Shrimps & A & -0.2038 & 0.0825 & 0.0135 & -0.1855 & 0.0825 & 0.0246 & -0.2085 & 0.0689 & 0.0025 \\
\hline Shrimps & B & 0.0128 & 0.4673 & 0.9782 & 0.0889 & 0.4675 & 0.8492 & 0.1553 & 0.2876 & 0.5893 \\
\hline Shrimps & C & 0.2934 & 0.4998 & 0.5572 & 0.2182 & 0.5001 & 0.6626 & 0.1947 & 0.3108 & 0.5311 \\
\hline Shrimps & $\mathrm{D}$ & -0.1115 & 0.0635 & 0.0792 & -0.0993 & 0.0635 & 0.1180 & -0.1183 & 0.0608 & 0.0520 \\
\hline Marinated fish and shellfish & A & 0.1905 & 0.1588 & 0.2305 & 0.3050 & 0.1551 & 0.0493 & 0.1908 & 0.1362 & 0.1611 \\
\hline Marinated fish and shellfish & B & -0.2788 & 0.1488 & 0.0611 & -0.3025 & 0.1487 & 0.0419 & -0.2517 & 0.1237 & 0.0419 \\
\hline Marinated fish and shellfish & C & 1,4621 & 0.3835 & 0.0001 & 1,3944 & 0.3832 & 0.0003 & 1,3555 & 0.3608 & 0.0002 \\
\hline Marinated fish and shellfish & D & $-1,4722$ & 0.4257 & 0.0005 & $-1,4301$ & 0.4257 & 0.0008 & $-1,3362$ & 0.3868 & 0.0006 \\
\hline Eggs and egg products & A & 0.2500 & 0.3701 & 0.4994 & 0.5426 & 0.3595 & 0.1313 & 0.3449 & 0.2744 & 0.2089 \\
\hline Eggs and egg products & B & -0.2920 & 0.3782 & 0.4402 & -0.5978 & 0.3668 & 0.1032 & -0.3813 & 0.2785 & 0.1710 \\
\hline Eggs and egg products & D & 0.0544 & 0.0537 & 0.3114 & 0.0760 & 0.0535 & 0.1554 & 0.0659 & 0.0459 & 0.1510 \\
\hline Vegetarian products, chilled & A & $-1,1428$ & 0.2785 & $<.0001$ & $-1,1136$ & 0.2788 & $<.0001$ & $-1,0669$ & 0.2677 & $<.0001$ \\
\hline Vegetarian products, chilled & B & 1,0995 & 0.2315 & $<.0001$ & 1,0056 & 0.2303 & $<.0001$ & 1,0243 & 0.2120 & $<.0001$ \\
\hline Vegetarian products, chilled & C & -0.0238 & 0.2387 & 0.9204 & 0.0481 & 0.2376 & 0.8394 & 0.0543 & 0.2126 & 0.7984 \\
\hline Vegetarian products, chilled & $\mathrm{D}$ & 0.0527 & 0.1127 & 0.6401 & 0.0450 & 0.1128 & 0.6902 & -0.0169 & 0.1046 & 0.8714 \\
\hline Milk UHT / fresh and plant-based drinks & A & 0.2146 & 0.2365 & 0.3641 & -0.0140 & 0.2260 & 0.9505 & 0.1690 & 0.1501 & 0.2601 \\
\hline Milk UHT / fresh and plant-based drinks & B & -0.5599 & 0.1969 & 0.0045 & -0.6320 & 0.1961 & 0.0013 & -0.5047 & 0.1689 & 0.0028 \\
\hline Milk UHT / fresh and plant-based drinks & C & 0.1230 & 0.1998 & 0.5381 & 0.3897 & 0.1825 & 0.0328 & 0.1118 & 0.0939 & 0.2342 \\
\hline Milk UHT / fresh and plant-based drinks & $\mathrm{D}$ & 0.1982 & 0.0542 & 0.0003 & 0.2298 & 0.0534 & $<.0001$ & 0.2010 & 0.0459 & $<.0001$ \\
\hline Yoghurt, soft white cheese and desserts & A & 0.2846 & 0.1254 & 0.0233 & 0.2959 & 0.1255 & 0.0184 & 0.1853 & 0.0819 & 0.0236 \\
\hline Yoghurt, soft white cheese and desserts & B & -0.0456 & 0.1798 & 0.8000 & 0.0850 & 0.1760 & 0.6294 & -0.0444 & 0.1079 & 0.6808 \\
\hline Yoghurt, soft white cheese and desserts & C & -0.3285 & 0.1905 & 0.0848 & -0.3649 & 0.1904 & 0.0554 & -0.2383 & 0.1049 & 0.0232 \\
\hline Yoghurt, soft white cheese and desserts & $\mathrm{D}$ & 0.2027 & 0.1254 & 0.1061 & 0.1153 & 0.1221 & 0.3450 & 0.2632 & 0.0743 & 0.0004 \\
\hline Yoghurt, soft white cheese and desserts & E & -0.1632 & 0.0732 & 0.0258 & -0.1629 & 0.0732 & 0.0262 & -0.1884 & 0.0497 & 0.0002 \\
\hline Ingredients dairy & A & $-1,5217$ & 0.7654 & 0.0487 & $-1,5850$ & 0.7654 & 0.0402 & $-1,4003$ & 0.6491 & 0.0346 \\
\hline Ingredients dairy & B & -0.0121 & 0.0777 & 0.8762 & -0.0160 & 0.0777 & 0.8371 & 0.0371 & 0.0672 & 0.5803 \\
\hline Ingredients dairy & C & -0.7586 & 0.2728 & 0.0054 & -0.6417 & 0.2707 & 0.0178 & -0.8870 & 0.1683 & $<.0001$ \\
\hline Ingredients dairy & $\mathrm{D}$ & 1,1407 & 0.2789 & $<.0001$ & 1,0247 & 0.2767 & 0.0002 & 1,2328 & 0.1780 & $<.0001$ \\
\hline Ingredients dairy & E & -0.1859 & 0.0608 & 0.0022 & -0.1745 & 0.0608 & 0.0041 & -0.2016 & 0.0581 & 0.0005 \\
\hline Cheeses & A & -0.0121 & 0.0090 & 0.1820 & -0.0101 & 0.0091 & 0.2677 & -0.0075 & 0.0088 & 0.3980 \\
\hline Cheeses & C & 0.1762 & 0.1289 & 0.1718 & 0.2221 & 0.1282 & 0.0834 & 0.0260 & 0.0512 & 0.6112 \\
\hline Cheeses & D & 0.0425 & 0.1280 & 0.7396 & -0.0003 & 0.1273 & 0.9981 & 0.1874 & 0.0621 & 0.0026 \\
\hline Cheeses & E & -0.2177 & 0.0469 & $<.0001$ & -0.2193 & 0.0470 & $<.0001$ & -0.2138 & 0.0391 & $<.0001$ \\
\hline Ice-cream and frozen desserts & A & -0.3340 & 0.1636 & 0.0412 & -0.5417 & 0.1525 & 0.0004 & -0.3092 & 0.0776 & $<.0001$ \\
\hline Ice-cream and frozen desserts & B & 0.4221 & 0.1756 & 0.0162 & 0.4583 & 0.1753 & 0.0090 & 0.3511 & 0.1091 & 0.0013 \\
\hline Ice-cream and frozen desserts & C & 0.1622 & 0.2412 & 0.5014 & 0.2189 & 0.2412 & 0.3643 & 0.1323 & 0.1665 & 0.4269 \\
\hline Ice-cream and frozen desserts & $\mathrm{D}$ & -0.2685 & 0.3040 & 0.3771 & -0.2351 & 0.3039 & 0.4391 & -0.1637 & 0.2190 & 0.4547 \\
\hline Ice-cream and frozen desserts & $E$ & 0.0361 & 0.1725 & 0.8342 & 0.1163 & 0.1712 & 0.4967 & -0.0027 & 0.1326 & 0.9838 \\
\hline Frozen French fries and potato products & A & 1,4112 & 0.5543 & 0.0109 & 1,7677 & 0.5458 & 0.0012 & 0.8477 & 0.2415 & 0.0005 \\
\hline Frozen French fries and potato products & B & -0.7917 & 0.4046 & 0.0504 & $-1,1252$ & 0.3935 & 0.0043 & -0.5076 & 0.2289 & 0.0266 \\
\hline Frozen French fries and potato products & C & -0.6742 & 0.1944 & 0.0005 & -0.6381 & 0.1944 & 0.0010 & -0.4908 & 0.1489 & 0.0010 \\
\hline Frozen French fries and potato products & $\mathrm{D}$ & 0.0593 & 0.1487 & 0.6900 & 0.0230 & 0.1483 & 0.8768 & 0.1488 & 0.1152 & 0.1965 \\
\hline Frozen Pizzas and prepared meals & A & 0.0091 & 0.1199 & 0.9398 & 0.0337 & 0.1200 & 0.7791 & 0.1003 & 0.0918 & 0.2749 \\
\hline Frozen Pizzas and prepared meals & B & -0.3454 & 0.2728 & 0.2055 & -0.3334 & 0.2731 & 0.2223 & -0.4581 & 0.1918 & 0.0169 \\
\hline Frozen Pizzas and prepared meals & C & -0.4441 & 0.2499 & 0.0756 & -0.3418 & 0.2477 & 0.1676 & -0.6105 & 0.1960 & 0.0018 \\
\hline Frozen Pizzas and prepared meals & $\mathrm{D}$ & 0.8190 & 0.3155 & 0.0095 & 0.6962 & 0.3140 & 0.0266 & 0.9901 & 0.1843 & $<.0001$ \\
\hline Frozen Pizzas and prepared meals & E & -0.0108 & 0.0514 & 0.8335 & -0.0192 & 0.0515 & 0.7098 & -0.0130 & 0.0409 & 0.7507 \\
\hline
\end{tabular}


Table 8 (continued)

\begin{tabular}{|c|c|c|c|c|c|c|c|c|c|c|}
\hline \multirow[t]{2}{*}{ Food category } & \multirow[t]{2}{*}{ Nutri-Score } & \multicolumn{3}{|c|}{ Unadjusted } & \multicolumn{3}{|c|}{$\begin{array}{l}\text { Adjusted for region, } \\
\text { cluster, non-food sales }\end{array}$} & \multicolumn{3}{|c|}{$\begin{array}{l}\text { Adjusted for region, } \\
\text { cluster, non-food sales, } \\
\text { week of the year }\end{array}$} \\
\hline & & Estimate & StdErr & $p$ & Estimate & StdErr & $p$ & Estimate & StdErr & $p$ \\
\hline Prepared meals canned ambient & A & -0.5470 & 0.4905 & 0.2648 & -0.5033 & 0.4909 & 0.3053 & -0.2953 & 0.4770 & 0.5360 \\
\hline Prepared meals canned ambient & B & $-1,4361$ & 0.5189 & 0.0057 & $-1,4405$ & 0.5194 & 0.0056 & $-1,5831$ & 0.5010 & 0.0016 \\
\hline Prepared meals canned ambient & C & 2,3508 & 0.4102 & $<.0001$ & 2,4037 & 0.4102 & $<.0001$ & 2,1441 & 0.3956 & $<.0001$ \\
\hline Prepared meals canned ambient & $\mathrm{D}$ & $-2,3101$ & 0.5062 & $<.0001$ & $-2,3002$ & 0.5061 & $<.0001$ & $-2,1321$ & 0.4673 & $<.0001$ \\
\hline Aperitif snacks (i.e. chips, salted biscuits) & A & -0.2263 & 0.0763 & 0.0030 & -0.2567 & 0.0758 & 0.0007 & -0.3007 & 0.0582 & $<.0001$ \\
\hline Aperitif snacks (i.e. chips, salted biscuits) & $\mathrm{B}$ & -0.1151 & 0.0392 & 0.0033 & -0.1094 & 0.0392 & 0.0052 & -0.1242 & 0.0368 & 0.0007 \\
\hline Aperitif snacks (i.e. chips, salted biscuits) & C & 0.2406 & 0.2091 & 0.2498 & 0.2520 & 0.2092 & 0.2286 & 0.2870 & 0.1414 & 0.0424 \\
\hline Aperitif snacks (i.e. chips, salted biscuits) & $\mathrm{D}$ & 0.1957 & 0.2103 & 0.3521 & 0.2527 & 0.2097 & 0.2282 & 0.1517 & 0.1436 & 0.2910 \\
\hline Aperitif snacks (i.e. chips, salted biscuits) & $E$ & -0.1016 & 0.1220 & 0.4048 & -0.1448 & 0.1214 & 0.2332 & -0.0167 & 0.0869 & 0.8478 \\
\hline Apero, chilled (cheese, salami, humus, olives etc.) & A & 0.2961 & 0.5323 & 0.5780 & 0.8249 & 0.5085 & 0.1048 & 0.0208 & 0.3742 & 0.9556 \\
\hline Apero, chilled (cheese, salami, humus, olives etc.) & B & -0.1694 & 0.3539 & 0.6323 & 0.1532 & 0.3347 & 0.6471 & -0.2715 & 0.2439 & 0.2656 \\
\hline Apero, chilled (cheese, salami, humus, olives etc.) & C & -0.5789 & 0.4463 & 0.1946 & -0.4948 & 0.4464 & 0.2677 & -0.6093 & 0.3050 & 0.0458 \\
\hline Apero, chilled (cheese, salami, humus, olives etc.) & $\mathrm{D}$ & -0.0173 & 0.4934 & 0.9720 & -0.5520 & 0.4637 & 0.2339 & 0.3401 & 0.3491 & 0.3300 \\
\hline Apero, chilled (cheese, salami, humus, olives etc.) & $E$ & -0.1320 & 0.3025 & 0.6627 & -0.4445 & 0.2893 & 0.1244 & -0.0068 & 0.2338 & 0.9769 \\
\hline Frozen vegetables and soups & A & 0.6131 & 0.2124 & 0.0039 & 0.6354 & 0.2126 & 0.0028 & 0.5572 & 0.1747 & 0.0014 \\
\hline Frozen vegetables and soups & B & -0.7845 & 0.1724 & $<.0001$ & -0.7955 & 0.1725 & $<.0001$ & -0.7033 & 0.1406 & $<.0001$ \\
\hline Frozen vegetables and soups & C & 0.1549 & 0.1054 & 0.1417 & 0.1474 & 0.1055 & 0.1623 & 0.1291 & 0.1006 & 0.1993 \\
\hline Frozen vegetables and soups & $E$ & 0.0747 & 0.0601 & 0.2143 & 0.0706 & 0.0599 & 0.2392 & 0.1014 & 0.0554 & 0.0673 \\
\hline Canned vegetables & A & 0.0068 & 0.0705 & 0.9227 & 0.0214 & 0.0704 & 0.7613 & -0.0585 & 0.0603 & 0.3319 \\
\hline Canned vegetables & B & -0.0581 & 0.0544 & 0.2856 & -0.0701 & 0.0543 & 0.1965 & -0.0074 & 0.0484 & 0.8781 \\
\hline Canned vegetables & C & 0.0511 & 0.0441 & 0.2460 & 0.0488 & 0.0441 & 0.2684 & 0.0655 & 0.0386 & 0.0897 \\
\hline Ready-to-use fresh vegetables, potatoes & A & 0.4015 & 0.0845 & $<.0001$ & 0.3975 & 0.0846 & $<.0001$ & 0.3962 & 0.0744 & $<.0001$ \\
\hline Ready-to-use fresh vegetables, potatoes & $\mathrm{B}$ & -0.1573 & 0.0571 & 0.0059 & -0.1759 & 0.0569 & 0.0020 & -0.1752 & 0.0443 & $<.0001$ \\
\hline Ready-to-use fresh vegetables, potatoes & C & -0.1448 & 0.0423 & 0.0006 & -0.1230 & 0.0419 & 0.0033 & -0.1409 & 0.0383 & 0.0002 \\
\hline Ready-to-use fresh vegetables, potatoes & $\mathrm{D}$ & -0.0956 & 0.0274 & 0.0005 & -0.0894 & 0.0273 & 0.0011 & -0.0656 & 0.0263 & 0.0126 \\
\hline Soups, canned & A & 0.2107 & 0.1181 & 0.0745 & 0.1597 & 0.1173 & 0.1735 & 0.2037 & 0.0995 & 0.0407 \\
\hline Soups, canned & B & -0.5133 & 0.3305 & 0.1205 & -0.4689 & 0.3307 & 0.1563 & -0.3815 & 0.2743 & 0.1643 \\
\hline Soups, canned & $C$ & 0.3264 & 0.3224 & 0.3114 & 0.3842 & 0.3219 & 0.2327 & 0.2176 & 0.2738 & 0.4268 \\
\hline Soups, canned & $D$ & -0.2112 & 0.0831 & 0.0110 & -0.2443 & 0.0825 & 0.0031 & -0.2187 & 0.0757 & 0.0039 \\
\hline Soups, canned & $E$ & 0.1663 & 0.0776 & 0.0321 & 0.1538 & 0.0776 & 0.0475 & 0.1551 & 0.0732 & 0.0341 \\
\hline Fresh fruit & A & 0.0391 & 0.0057 & $<.0001$ & 0.0410 & 0.0056 & $<.0001$ & 0.03894 & 0.0052 & $<.0001$ \\
\hline Fresh fruit & $\mathrm{B}$ & -0.0025 & 0.0054 & 0.6430 & -0.0041 & 0.0054 & 0.4463 & -0.00230 & 0.0041 & 0.5746 \\
\hline Fresh fruit & C & -0.0370 & 0.0071 & $<.0001$ & -0.0371 & 0.0071 & $<.0001$ & -0.0357 & 0.0068 & $<.0001$ \\
\hline Canned fruit & A & 0.2105 & 0.4202 & 0.6164 & 0.3451 & 0.4189 & 0.4100 & -0.2449 & 0.2540 & 0.3350 \\
\hline Canned fruit & B & 0.3954 & 0.2753 & 0.1510 & 0.5164 & 0.2732 & 0.0588 & 0.5992 & 0.2099 & 0.0043 \\
\hline Canned fruit & $C$ & -0.6337 & 0.2891 & 0.0284 & -0.8637 & 0.2810 & 0.0021 & -0.4091 & 0.1734 & 0.0184 \\
\hline Canned fruit & $\mathrm{D}$ & 0.0749 & 0.1142 & 0.5121 & 0.0622 & 0.1145 & 0.5871 & 0.2013 & 0.0951 & 0.0345 \\
\hline Dried fruit (including nuts) & A & -0.8127 & 0.2967 & 0.0062 & -0.9576 & 0.2929 & 0.0011 & -0.7125 & 0.2619 & 0.0065 \\
\hline Dried fruit (including nuts) & $\mathrm{B}$ & 1,5572 & 0.3774 & $<.0001$ & 1,6883 & 0.3751 & $<.0001$ & 1,7205 & 0.3269 & $<.0001$ \\
\hline Dried fruit (including nuts) & $C$ & $-1,1118$ & 0.2584 & $<.0001$ & $-1,0923$ & 0.2587 & $<.0001$ & $-1,2457$ & 0.2255 & $<.0001$ \\
\hline Dried fruit (including nuts) & $\mathrm{D}$ & 0.4126 & 0.1423 & 0.0037 & 0.4152 & 0.1424 & 0.0036 & 0.2910 & 0.1280 & 0.0230 \\
\hline Dried fruit (including nuts) & $E$ & -0.0783 & 0.0234 & 0.0008 & -0.0730 & 0.0232 & 0.0017 & -0.0907 & 0.0229 & $<.0001$ \\
\hline Bread preparations (i.e. crackers, rusks) & A & 0.0440 & 0.2506 & 0.8607 & 0.1100 & 0.2499 & 0.6599 & -0.0801 & 0.1948 & 0.6809 \\
\hline Bread preparations (i.e. crackers, rusks) & $\mathrm{B}$ & 0.0789 & 0.2032 & 0.6980 & 0.1195 & 0.2030 & 0.5560 & 0.0150 & 0.1837 & 0.9347 \\
\hline Bread preparations (i.e. crackers, rusks) & C & -0.7703 & 0.3248 & 0.0177 & -0.6024 & 0.3212 & 0.0608 & -0.8263 & 0.2745 & 0.0026 \\
\hline Bread preparations (i.e. crackers, rusks) & $\mathrm{D}$ & 0.6310 & 0.2558 & 0.0137 & 0.5367 & 0.2541 & 0.0347 & 0.6705 & 0.2252 & 0.0029 \\
\hline Bread preparations (i.e. crackers, rusks) & $E$ & 0.0060 & 0.2438 & 0.9805 & -0.1614 & 0.2386 & 0.4989 & 0.2314 & 0.1733 & 0.1817 \\
\hline
\end{tabular}


Table 8 (continued)

\begin{tabular}{|c|c|c|c|c|c|c|c|c|c|c|}
\hline \multirow[t]{2}{*}{ Food category } & \multirow[t]{2}{*}{ Nutri-Score } & \multicolumn{3}{|c|}{ Unadjusted } & \multicolumn{3}{|c|}{$\begin{array}{l}\text { Adjusted for region, } \\
\text { cluster, non-food sales }\end{array}$} & \multicolumn{3}{|c|}{$\begin{array}{l}\text { Adjusted for region, } \\
\text { cluster, non-food sales, } \\
\text { week of the year }\end{array}$} \\
\hline & & Estimate & StdErr & $p$ & Estimate & StdErr & $p$ & Estimate & StdErr & $p$ \\
\hline Sweet Bread toppings (chocolate, jam, honey) & A & 0.0053 & 0.0557 & 0.9240 & 0.0117 & 0.0558 & 0.8337 & 0.0164 & 0.0544 & 0.7625 \\
\hline Sweet Bread toppings (chocolate, jam, honey) & $\mathrm{B}$ & 0.0669 & 0.0641 & 0.2967 & 0.0751 & 0.0642 & 0.2413 & 0.0893 & 0.0575 & 0.1209 \\
\hline Sweet Bread toppings (chocolate, jam, honey) & C & 0.5599 & 0.1829 & 0.0022 & 0.6189 & 0.1823 & 0.0007 & 0.4750 & 0.1377 & 0.0006 \\
\hline Sweet Bread toppings (chocolate, jam, honey) & $\mathrm{D}$ & -0.1130 & 0.2210 & 0.6092 & -0.1847 & 0.2198 & 0.4008 & 0.0375 & 0.1784 & 0.8334 \\
\hline Sweet Bread toppings (chocolate, jam, honey) & $\mathrm{E}$ & -0.5709 & 0.2070 & 0.0059 & -0.5546 & 0.2072 & 0.0074 & -0.6545 & 0.1680 & $<.0001$ \\
\hline Spreadable salads (i.e. meat, crab, etc.) & B & -0.1509 & 0.1326 & 0.2553 & -0.1200 & 0.1325 & 0.3651 & -0.1773 & 0.1193 & 0.1374 \\
\hline Spreadable salads (i.e. meat, crab, etc.) & C & 0.3859 & 0.1990 & 0.0525 & 0.5075 & 0.1958 & 0.0096 & 0.3759 & 0.1656 & 0.0233 \\
\hline Spreadable salads (i.e. meat, crab, etc.) & $\mathrm{D}$ & -0.2452 & 0.2384 & 0.3037 & -0.4044 & 0.2344 & 0.0845 & -0.2272 & 0.1885 & 0.2281 \\
\hline Breakfast cereals & A & -0.2902 & 0.2950 & 0.3253 & -0.5973 & 0.2816 & 0.0340 & -0.1351 & 0.1704 & 0.4280 \\
\hline Breakfast cereals & $\mathrm{B}$ & -0.3037 & 0.1370 & 0.0267 & -0.3168 & 0.1371 & 0.0209 & -0.3361 & 0.1166 & 0.0039 \\
\hline Breakfast cereals & C & 0.0093 & 0.2967 & 0.9751 & 0.2545 & 0.2889 & 0.3784 & -0.0299 & 0.2076 & 0.8856 \\
\hline Breakfast cereals & $D$ & 0.2795 & 0.2498 & 0.2634 & 0.3468 & 0.2493 & 0.1643 & 0.1850 & 0.1854 & 0.3184 \\
\hline Breakfast cereals & $E$ & 0.1854 & 0.1014 & 0.0676 & 0.1946 & 0.1014 & 0.0549 & 0.1951 & 0.0883 & 0.0271 \\
\hline Sweet biscuits & A & -0.0510 & 0.0114 & $<.0001$ & -0.0513 & 0.0113 & $<.0001$ & -0.0517 & 0.0111 & $<.0001$ \\
\hline Sweet biscuits & $\mathrm{B}$ & -0.0310 & 0.0265 & 0.2422 & -0.0365 & 0.0265 & 0.1686 & -0.0480 & 0.0225 & 0.0327 \\
\hline Sweet biscuits & C & -0.1328 & 0.1615 & 0.4111 & -0.1366 & 0.1616 & 0.3978 & -0.0338 & 0.1417 & 0.8112 \\
\hline Sweet biscuits & $D$ & -0.2728 & 0.1785 & 0.1264 & -0.2840 & 0.1787 & 0.1120 & -0.1601 & 0.1274 & 0.2091 \\
\hline Sweet biscuits & $E$ & 0.5433 & 0.1915 & 0.0046 & 0.6027 & 0.1912 & 0.0016 & 0.4927 & 0.1437 & 0.0006 \\
\hline Bread & A & $-2,4176$ & 0.4003 & $<.0001$ & $-2,7543$ & 0.3881 & $<.0001$ & $-2,5210$ & 0.3135 & $<.0001$ \\
\hline Bread & B & 3,1918 & 0.4632 & $<.0001$ & 3,7976 & 0.4279 & $<.0001$ & 3,0777 & 0.3335 & $<.0001$ \\
\hline Bread & C & -0.3397 & 0.1581 & 0.0317 & -0.4403 & 0.1556 & 0.0047 & -0.3213 & 0.1089 & 0.0032 \\
\hline Bread & $\mathrm{D}$ & -0.4137 & 0.1798 & 0.0215 & -0.5685 & 0.1741 & 0.0011 & -0.2227 & 0.1256 & 0.0763 \\
\hline Bread & $E$ & -0.0169 & 0.0241 & 0.4817 & -0.0291 & 0.0238 & 0.2224 & -0.0086 & 0.0175 & 0.6236 \\
\hline Viennese cakes and buns & C & 0.1585 & 0.1064 & 0.1361 & 0.1656 & 0.1065 & 0.1200 & 0.1626 & 0.0944 & 0.0851 \\
\hline Viennese cakes and buns & $\mathrm{D}$ & $-1,3587$ & 0.3353 & $<.0001$ & $-1,5010$ & 0.3327 & $<.0001$ & $-1,2374$ & 0.2753 & $<.0001$ \\
\hline Viennese cakes and buns & $\mathrm{E}$ & 1,1424 & 0.3374 & 0.0007 & 1,2784 & 0.3351 & 0.0001 & 1,0215 & 0.2753 & 0.0002 \\
\hline Cakes and pastries & B & -0.5809 & 0.0577 & $<.0001$ & -0.5890 & 0.0577 & $<.0001$ & -0.5995 & 0.0553 & $<.0001$ \\
\hline Cakes and pastries & C & -0.5268 & 0.4472 & 0.2388 & -0.4750 & 0.4474 & 0.2885 & -0.7537 & 0.2149 & 0.0005 \\
\hline Cakes and pastries & $\mathrm{D}$ & -0.6362 & 0.4215 & 0.1312 & -0.5929 & 0.4218 & 0.1599 & -0.3941 & 0.2388 & 0.0989 \\
\hline Cakes and pastries & $E$ & 1,4858 & 0.5046 & 0.0033 & 1,4032 & 0.5046 & 0.0054 & 1,4883 & 0.2866 & $<.0001$ \\
\hline Confectionery & A & 0.2202 & 0.0549 & $<.0001$ & 0.2360 & 0.0547 & $<.0001$ & 0.1971 & 0.0532 & 0.0002 \\
\hline Confectionery & B & 0.0455 & 0.1912 & 0.8119 & 0.0438 & 0.1914 & 0.8189 & 0.0138 & 0.1651 & 0.9335 \\
\hline Confectionery & $C$ & 0.3513 & 0.1149 & 0.0022 & 0.3269 & 0.1148 & 0.0044 & 0.2997 & 0.1021 & 0.0034 \\
\hline Confectionery & $\mathrm{D}$ & $-1,1470$ & 0.3439 & 0.0009 & $-1,2357$ & 0.3427 & 0.0003 & $-1,0050$ & 0.2398 & $<.0001$ \\
\hline Confectionery & $E$ & 0.5678 & 0.3554 & 0.1102 & 0.6599 & 0.3535 & 0.0620 & 0.5395 & 0.1985 & 0.0066 \\
\hline Chocolate and bars & C & 0.0812 & 0.0702 & 0.2492 & 0.0948 & 0.07441 & 0.2044 & 0.0788 & 0.0655 & 0.2315 \\
\hline Chocolate and bars & $\mathrm{D}$ & 0.2361 & 0.1227 & 0.0544 & 0.1638 & 0.1209 & 0.1756 & 0.1856 & 0.0946 & 0.0497 \\
\hline Chocolate and bars & $E$ & -0.2341 & 0.1230 & 0.0570 & -0.1603 & 0.1211 & 0.1858 & -0.1808 & 0.0948 & 0.0565 \\
\hline Pasta, rice and starch products & A & -0.0194 & 0.1824 & 0.9152 & -0.0353 & 0.1825 & 0.8465 & -0.0643 & 0.1437 & 0.6543 \\
\hline Pasta, rice and starch products & $\mathrm{B}$ & 0.1455 & 0.1317 & 0.2694 & 0.1935 & 0.1310 & 0.1397 & 0.1523 & 0.1052 & 0.1477 \\
\hline Pasta, rice and starch products & C & -0.1699 & 0.1138 & 0.1354 & -0.2371 & 0.1121 & 0.0345 & -0.1611 & 0.0910 & 0.0765 \\
\hline Pasta, rice and starch products & $\mathrm{D}$ & 0.0484 & 0.0501 & 0.3342 & 0.0838 & 0.0490 & 0.0873 & 0.0763 & 0.0419 & 0.0690 \\
\hline Oil and vinegar & A & -0.1361 & 0.1702 & 0.4250 & -0.1355 & 0.1714 & 0.4301 & -0.1287 & 0.2641 & 0.6269 \\
\hline Oil and vinegar & $\mathrm{B}$ & -0.0051 & 0.0256 & 0.8436 & 0.0065 & 0.0255 & 0.8002 & -0.0140 & 0.0234 & 0.5497 \\
\hline Oil and vinegar & C & 0.4768 & 0.2506 & 0.0571 & 0.4768 & 0.2508 & 0.0573 & 0.5741 & 0.2162 & 0.0080 \\
\hline Oil and vinegar & $\mathrm{D}$ & -0.6273 & 0.2650 & 0.0179 & -0.5995 & 0.2650 & 0.0237 & -0.7291 & 0.2254 & 0.0012 \\
\hline Oil and vinegar & $E$ & 0.2540 & 0.0759 & 0.0008 & 0.2386 & 0.0759 & 0.0017 & 0.2534 & 0.0693 & 0.0003 \\
\hline
\end{tabular}


Table 8 (continued)

\begin{tabular}{|c|c|c|c|c|c|c|c|c|c|c|}
\hline \multirow[t]{2}{*}{ Food category } & \multirow[t]{2}{*}{ Nutri-Score } & \multicolumn{3}{|c|}{ Unadjusted } & \multicolumn{3}{|c|}{$\begin{array}{l}\text { Adjusted for region, } \\
\text { cluster, non-food sales }\end{array}$} & \multicolumn{3}{|c|}{$\begin{array}{l}\text { Adjusted for region, } \\
\text { cluster, non-food sales, } \\
\text { week of the year }\end{array}$} \\
\hline & & Estimate & StdErr & $p$ & Estimate & StdErr & $p$ & Estimate & StdErr & $p$ \\
\hline Condiments and sauces & A & 0.0207 & 0.1621 & 0.8985 & 0.1884 & 0.1547 & 0.2234 & -0.0055 & 0.0866 & 0.9494 \\
\hline Condiments and sauces & B & 0.0811 & 0.1191 & 0.4958 & 0.1404 & 0.1175 & 0.2321 & 0.1292 & 0.0800 & 0.1063 \\
\hline Condiments and sauces & C & -0.5212 & 0.2513 & 0.0381 & -0.5925 & 0.2508 & 0.0182 & -0.2467 & 0.1332 & 0.0641 \\
\hline Condiments and sauces & $\mathrm{D}$ & 0.5276 & 0.3267 & 0.1064 & 0.4396 & 0.3260 & 0.1775 & 0.2666 & 0.1540 & 0.0835 \\
\hline Condiments and sauces & $E$ & -0.1035 & 0.1564 & 0.5083 & -0.1705 & 0.1548 & 0.2708 & -0.1480 & 0.0910 & 0.1036 \\
\hline World food & A & -0.2429 & 0.1971 & 0.2179 & -0.3628 & 0.1932 & 0.0604 & -0.2685 & 0.1698 & 0.1139 \\
\hline World food & B & 0.4007 & 0.2977 & 0.1784 & 0.6180 & 0.2905 & 0.0335 & 0.2968 & 0.2418 & 0.2198 \\
\hline World food & C & 0.3526 & 0.2741 & 0.1983 & 0.4665 & 0.2718 & 0.0861 & 0.3949 & 0.2523 & 0.1176 \\
\hline World food & D & 0.4252 & 0.2399 & 0.0763 & 0.2507 & 0.2341 & 0.2843 & 0.5186 & 0.2078 & 0.0126 \\
\hline World food & $E$ & -0.9461 & 0.1788 & $<.0001$ & -0.9743 & 0.1788 & $<.0001$ & -0.9378 & 0.1753 & $<.0001$ \\
\hline Sugar and sweeteners & B & 0.7737 & 0.2377 & 0.0011 & 0.8664 & 0.2355 & 0.0002 & 0.8014 & 0.2163 & 0.0002 \\
\hline Sugar and sweeteners & C & 0.3205 & 0.1854 & 0.0839 & 0.2861 & 0.1854 & 0.1230 & 0.2926 & 0.1730 & 0.0909 \\
\hline Sugar and sweeteners & D & $-1,1171$ & 0.2935 & 0.0001 & $-1,1397$ & 0.2936 & 0.0001 & $-1,1233$ & 0.2648 & $<.0001$ \\
\hline Sugar and sweeteners & $E$ & 0.9878 & 10.049 & 0.3272 & 1,2651 & 1,0093 & 0.2120 & 1,0767 & 1,6221 & 0.5091 \\
\hline Flour and dessert preparations & A & 0.1020 & 0.2939 & 0.7286 & 0.1035 & 0.2942 & 0.7251 & 0.3542 & 0.2480 & 0.1532 \\
\hline Flour and dessert preparations & B & -0.5819 & 0.2112 & 0.0059 & -0.5538 & 0.2112 & 0.0088 & -0.6586 & 0.1920 & 0.0006 \\
\hline Flour and dessert preparations & C & 0.3938 & 0.2978 & 0.1861 & 0.4310 & 0.2978 & 0.1480 & 0.4783 & 0.2696 & 0.0760 \\
\hline Flour and dessert preparations & $\mathrm{D}$ & 0.0003 & 0.3630 & 0.9994 & 0.0943 & 0.3619 & 0.7944 & -0.2926 & 0.2819 & 0.2993 \\
\hline Flour and dessert preparations & $E$ & 0.0835 & 0.2850 & 0.7697 & -0.0725 & 0.2820 & 0.7971 & 0.1127 & 0.2535 & 0.6565 \\
\hline Spreadable fats (i.e. butter, margarines) & C & -0.4370 & 0.1544 & 0.0047 & -0.3221 & 0.1508 & 0.0328 & -0.4964 & 0.0984 & $<.0001$ \\
\hline Spreadable fats (i.e. butter, margarines) & $\mathrm{D}$ & 0.0299 & 0.1953 & 0.8782 & 0.0532 & 0.1954 & 0.7853 & 0.0695 & 0.1381 & 0.6146 \\
\hline Spreadable fats (i.e. butter, margarines) & E & 0.4046 & 0.2144 & 0.0592 & 0.2689 & 0.2109 & 0.2022 & 0.4268 & 0.1466 & 0.0036 \\
\hline Juices, fresh, chilled & B & -0.1710 & 0.1053 & 0.1045 & -0.1871 & 0.1054 & 0.0758 & -0.2219 & 0.0845 & 0.0086 \\
\hline Juices, fresh, chilled & C & 0.8644 & 0.2612 & 0.0009 & 0.8439 & 0.2615 & 0.0013 & 0.9334 & 0.2108 & $<.0001$ \\
\hline Juices, fresh, chilled & D & -0.2266 & 0.1842 & 0.2188 & -0.2061 & 0.1843 & 0.2635 & -0.1970 & 0.1624 & 0.2253 \\
\hline Juices, fresh, chilled & E & -0.4700 & 0.1275 & 0.0002 & -0.4449 & 0.1274 & 0.0005 & -0.5288 & 0.1147 & $<.0001$ \\
\hline Fruit juices, ambient & A & $-1,0311$ & 0.1830 & $<.0001$ & -0.9741 & 0.1825 & $<.0001$ & -0.9697 & 0.1730 & $<.0001$ \\
\hline Fruit juices, ambient & B & -0.0839 & 0.0953 & 0.3790 & -0.0834 & 0.0954 & 0.3824 & -0.0506 & 0.0853 & 0.5529 \\
\hline Fruit juices, ambient & C & 0.9635 & 0.3448 & 0.0052 & 0.6901 & 0.3361 & 0.0401 & 0.8650 & 0.2617 & 0.0010 \\
\hline Fruit juices, ambient & $\mathrm{D}$ & 0.3907 & 0.1230 & 0.0015 & 0.4690 & 0.1211 & 0.0001 & 0.3813 & 0.1131 & 0.0008 \\
\hline Fruit juices, ambient & E & -0.2603 & 0.2619 & 0.3202 & -0.1130 & 0.2588 & 0.6624 & -0.2492 & 0.2017 & 0.2168 \\
\hline Waters (including flavored) & A & 0.0341 & 0.1552 & 0.8262 & -0.0599 & 0.1528 & 0.6954 & 0.1141 & 0.0942 & 0.2258 \\
\hline Waters (including flavored) & B & -0.0968 & 0.1538 & 0.5294 & -0.0122 & 0.1518 & 0.9360 & -0.1787 & 0.0921 & 0.0524 \\
\hline Waters (including flavored) & $\mathrm{D}$ & -0.0461 & 0.0654 & 0.4809 & -0.0412 & 0.0643 & 0.5220 & -0.1247 & 0.0617 & 0.0435 \\
\hline Waters (including flavored) & E & -0.0533 & 0.0316 & 0.0915 & -0.0488 & 0.0311 & 0.1172 & -0.0527 & 0.0317 & 0.0967 \\
\hline Soft drinks (light, zero, regular) & $A$ & -0.0207 & 0.0073 & 0.0047 & -0.0210 & 0.0073 & 0.0041 & -0.0159 & 0.0073 & 0.0293 \\
\hline Soft drinks (light, zero, regular) & B & 0.0409 & 0.1650 & 0.8043 & -0.0357 & 0.1638 & 0.8275 & 0.1402 & 0.1214 & 0.2482 \\
\hline Soft drinks (light, zero, regular) & C & -0.3746 & 0.0747 & $<.0001$ & -0.3982 & 0.0746 & $<.0001$ & -0.3861 & 0.0553 & $<.0001$ \\
\hline Soft drinks (light, zero, regular) & $\mathrm{D}$ & 0.4098 & 0.2075 & 0.0483 & 0.5017 & 0.2061 & 0.0150 & 0.2479 & 0.1348 & 0.0660 \\
\hline Soft drinks (light, zero, regular) & $E$ & -0.0770 & 0.1845 & 0.6765 & -0.0640 & 0.1847 & 0.7288 & 0.0072 & 0.1496 & 0.9617 \\
\hline Syrups & B & 0.5046 & 0.2314 & 0.0293 & 0.5781 & 0.2308 & 0.0123 & 0.5246 & 0.2250 & 0.0198 \\
\hline Syrups & C & 1,1152 & 0.5610 & 0.0469 & 12119 & 0.5604 & 0.0306 & 1,2054 & 0.4639 & 0.0094 \\
\hline Syrups & $\mathrm{D}$ & -0.4343 & 0.2222 & 0.0507 & -0.4317 & 0.2224 & 0.0523 & -0.3565 & 0.1993 & 0.0737 \\
\hline Syrups & $E$ & -0.9215 & 0.5711 & 0.1067 & $-1,0027$ & 0.5709 & 0.0791 & $-1,0742$ & 0.4919 & 0.0290 \\
\hline Non -alcoholic drinks & B & 0.2561 & 10.843 & 0.8133 & 1,1072 & 1,0572 & 0.2950 & 0.3784 & 0.9991 & 0.7049 \\
\hline Non -alcoholic drinks & C & -0.1647 & 0.4858 & 0.7345 & 0.1024 & 0.4773 & 0.8301 & -0.1387 & 0.4642 & 0.7651 \\
\hline Non -alcoholic drinks & D & -0.4080 & 1,1724 & 0.7279 & -0.8093 & 1,1673 & 0.4882 & -0.5039 & 1,0561 & 0.6333 \\
\hline
\end{tabular}


Table 8 (continued)

\begin{tabular}{|c|c|c|c|c|c|c|c|c|c|c|}
\hline \multirow[t]{2}{*}{ Food category } & \multirow[t]{2}{*}{ Nutri-Score } & \multicolumn{3}{|c|}{ Unadjusted } & \multicolumn{3}{|c|}{$\begin{array}{l}\text { Adjusted for region, } \\
\text { cluster, non-food sales }\end{array}$} & \multicolumn{3}{|c|}{$\begin{array}{l}\text { Adjusted for region, } \\
\text { cluster, non-food sales, } \\
\text { week of the year }\end{array}$} \\
\hline & & Estimate & StdErr & $p$ & Estimate & StdErr & $p$ & Estimate & StdErr & $p$ \\
\hline Non-alcoholic drinks & $E$ & 0.0227 & 1,0276 & 0.9824 & 0.2137 & 1,0280 & 0.8353 & 0.3086 & 0.9147 & 0.7358 \\
\hline Apero \& Appetizers & A & -0.0427 & 0.7542 & 0.9549 & 0.2754 & 0.7508 & 0.7138 & $-1,2070$ & 0.3342 & 0.0003 \\
\hline Apero \& Appetizers & B & 0.0276 & 0.6326 & 0.9652 & -0.1827 & 0.6292 & 0.7715 & 0.0803 & 0.3325 & 0.8091 \\
\hline Apero \& Appetizers & C & 0.1253 & 0.4794 & 0.7938 & 0.4156 & 0.4720 & 0.3786 & 0.2019 & 0.3365 & 0.5485 \\
\hline Apero \& Appetizers & D & 0.0145 & 0.6484 & 0.9822 & -0.1044 & 0.6486 & 0.8721 & 0.3698 & 0.5233 & 0.4798 \\
\hline Apero \& Appetizers & $\mathrm{E}$ & -0.0098 & 0.7030 & 0.9888 & -0.0917 & 0.7017 & 0.8960 & 0.7058 & 0.4353 & 0.1050 \\
\hline Meals to cook and heat (i.e. lasagna, goulash) & A & 0.2759 & 0.3518 & 0.4329 & 0.4418 & 0.3472 & 0.2032 & 0.1752 & 0.1687 & 0.2990 \\
\hline Meals to cook and heat (i.e. lasagna, goulash) & B & -0.1286 & 0.3433 & 0.7080 & -0.3628 & 0.3364 & 0.2809 & -0.0452 & 0.1790 & 0.8008 \\
\hline Meals to cook and heat (i.e. lasagna, goulash) & C & 0.0887 & 0.2685 & 0.7412 & -0.0055 & 0.2674 & 0.9837 & 0.0517 & 0.1583 & 0.7440 \\
\hline Meals to cook and heat (i.e. lasagna, goulash) & $\mathrm{D}$ & -0.1961 & 0.3360 & 0.5595 & -0.0537 & 0.3342 & 0.8723 & -0.1528 & 0.1444 & 0.2899 \\
\hline Meals to cook and heat (i.e. lasagna, goulash) & $E$ & -0.0197 & 0.0234 & 0.3991 & -0.0160 & 0.0234 & 0.4943 & -0.0333 & 0.0207 & 0.1083 \\
\hline Meals to go (i.e. wraps, salads, sandwiches) & A & 1,0659 & 0.2883 & 0.0002 & 0.9520 & 0.2870 & 0.0009 & 1,1751 & 0.2337 & $<.0001$ \\
\hline Meals to go (i.e. wraps, salads, sandwiches) & B & -0.9809 & 0.2219 & $<.0001$ & -0.9635 & 0.2221 & $<.0001$ & $-1,0362$ & 0.2088 & $<.0001$ \\
\hline Meals to go (i.e. wraps, salads, sandwiches) & C & -0.1589 & 0.2537 & 0.5310 & -0.0927 & 0.2533 & 0.7145 & -0.1903 & 0.2260 & 0.3998 \\
\hline Meals to go (i.e. wraps, salads, sandwiches) & $\mathrm{D}$ & 0.1319 & 0.0521 & 0.0114 & 0.1555 & 0.0518 & 0.0027 & 0.1560 & 0.0447 & 0.0005 \\
\hline Meals to go (i.e. wraps, salads, sandwiches) & $E$ & -0.0474 & 0.0505 & 0.3479 & 0.0157 & 0.0472 & 0.7391 & -0.0351 & 0.0376 & 0.3515 \\
\hline Meals concept \& event & B & -0.5691 & 0.1671 & 0.0007 & -0.5994 & 0.1672 & 0.0003 & -0.6043 & 0.1592 & 0.0001 \\
\hline Meals concept \& event & C & 0.1592 & 0.3296 & 0.6291 & 0.3102 & 0.3264 & 0.3420 & 0.1154 & 0.3164 & 0.7154 \\
\hline Meals concept \& event & D & 1,1520 & 0.2988 & 0.0001 & 1,1094 & 0.2991 & 0.0002 & 1,2854 & 0.2842 & $<.0001$ \\
\hline Meals to compose & A & -0.0130 & 0.2756 & 0.9624 & -0.1617 & 0.2707 & 0.5501 & 0.2553 & 0.1686 & 0.1299 \\
\hline Meals to compose & B & 1,7429 & 0.3933 & $<.0001$ & 1,8010 & 0.3934 & $<.0001$ & 2,0784 & 0.3562 & $<.0001$ \\
\hline Meals to compose & C & $-1,7789$ & 0.4506 & $<.0001$ & $-1,6561$ & 0.4494 & 0.0002 & $-2,2211$ & 0.3690 & $<.0001$ \\
\hline Meals to compose & $\mathrm{D}$ & -0.3035 & 0.0894 & 0.0007 & -0.2729 & 0.0882 & 0.0020 & -0.2735 & 0.0866 & 0.0016 \\
\hline
\end{tabular}




\section{Abbreviations}

ESL: Electronic shelf labels; FOP: Front-of-pack; FVNL: Fruit vegetables nuts legumes; MTL: Multiple Traffic Lights; WHO: World Health Organization.

\section{Acknowledgements}

The authors want to acknowledge Delhaize for providing the sales data needed for the analyses of this study.

\section{Authors' contributions}

S.V. initiated and designed the study, conducted the analysis and wrote the paper. N.B. provided input for the statistical analysis, interpretation of the results and revised draft versions of the paper. All authors approved the final version of the manuscript.

\section{Funding}

No funding was received for this study.

\section{Availability of data and materials}

The sales data that support the findings of this study are available from Delhaize but restrictions apply to the availability of these data, which were used under license for the current study, and so are not publicly available. The data are however available from the authors upon reasonable request and with permission of Delhaize.

\section{Declarations}

Ethics approval and consent to participate

Not applicable.

\section{Consent for publication}

Not applicable.

\section{Competing interests}

The authors declare that they have no competing interests.

Received: 26 February 2021 Accepted: 29 September 2021

Published online: 18 November 2021

\section{References}

1. World Health Organization. Global action plan for the prevention and control of non communicable diseases 2013-2020. Geneva: World Health Organization; 2013.

2. Kelly $B$, Jewell J. What is the evidence on the policy specifications, development processes and effectiveness of existing front-of-pack food labelling policies in the WHO European region? Copenhagen: World Health Organization Europe; 2018.

3. Vandevijvere S. Uptake of Nutri-Score during the first year of implementation in Belgium. Arch Public Health. 2020;78:107.

4. Julia C, Hercberg S, Europe WHO. Development of a new front-of-pack nutrition label in France: the five-colour Nutri-score. Public Health Panorama. 2017;03(04):712-25.

5. Santé Publique France. Nutri-Score. 2021. https://www.santepubliquefr ance.fr/en/Nutri-Score.

6. Vandevijvere S, Vermote M, Egnell M, Galan P, Talati Z, Pettigrew S, et al. Consumers' food choices, understanding and perceptions in response to different front-of-pack nutrition labelling systems in Belgium: results from an online experimental study. Arch Public Health. 2020;78:30. https://doi.org/10.1186/s13690-020-00404-3 eCollection 2020.

7. Ducrot P, Julia C, Mejean C, Kesse-Guyot E, Touvier M, Fezeu LK, et al. Impact of different front-of-pack nutrition labels on consumer purchasing intentions: a randomized controlled trial. Am J Prev Med. 2016;50(5):627-36.

8. Julia C, Blanchet O, Mejean C, Peneau S, Ducrot P, Alles B, et al. Impact of the front-of-pack 5-colour nutrition label (5-CNL) on the nutritional quality of purchases: an experimental study. Int J Behav Nutr Phys Act. 2016;13/1:101.

9. Deschasaux M, Huybrechts I, Julia C, Hercberg S, Egnell M, Srour B, et al. Association between nutritional profiles of foods underlying
Nutri-score front-of-pack labels and mortality: EPIC cohort study in 10 European countries. BMJ. 2020;370:m3173.

10. Euromonitor. Euromonitor Belgium. 2018. Available from https://www. euromonitor.com/belgium.

11. Chan J, McMahon E, Brimblecombe J. Point-of-sale nutrition information interventions in food retail stores to promote healthier food purchase and intake: a systematic review. Obes Rev. 2021. https://doi. org/10.1111/obr.13311 Online ahead of print.

12. Wing C, Simon K, Bello-Gomez R. Designing difference in difference studies: best practices for public health policy research. Annu Rev Public Health. 2018; PMID: 29328877.

13. Temple NJ. Front-of-package food labels: A narrative review. Appetite. 2020; PMID: 31605724. Review.

14. Sacks G, Rayner M, Swinburn B. Impact of front-of-pack 'traffic-light' nutrition labelling on consumer food purchases in the UK. Health Promot Int. 2009;24:344-52.

15. Sacks G, Tikellis K, Millar L, Swinburn B. Impact of 'traffic-light' nutrition information on online food purchases in Australia. Aust N Z J Public Health. 2011;35:122-6.

16. Hoenink JC, Stuber JM, Lakerveld J, Waterlander W, Beulens JWJ, Mackenbach JD. The effect of on-shelf sugar labeling on beverage sales in the supermarket: a comparative interrupted time series analysis of a natural experiment. Int J Behav Nutr Phys Act. 2021;18(1):49.

17. Hobin E, Bollinger B, Sacco J, Liebman E, Vanderlee L, Zuo F, et al. Consumers' response to an on-shelf nutrition labelling system in supermarkets: evidence to inform policy and practice. Milbank Q. 2017;95:494-534.

18. Rahkovsky I, Lin BH, Lin CTJ, Lee JY. Effects of the guiding stars program on purchases of ready-to-eat cereals with different nutritional attributes. Food Policy. 2013;43:100-7.

19. Finkelstein EA, Li W, Melo G, Strombotne K, Zhen C. Identifying the effect of shelf nutrition labels on consumer purchases: results of a natural experiment and consumer survey. Am J Clin Nutr. 2018;107(4):647-51. https://doi.org/10.1093/ajcn/nqy014.

20. Thorndike A. Healthy choice architecture in the supermarket: does it work? Soc Sci Med. 2020;266:113459.

21. Egnell M, Ducrot P, Touvier M, Allès B, Hercberg S, Kesse-Guyot E, et al. Objective understanding of Nutri-score front-of-package nutrition label according to individual characteristics of subjects: comparisons with other format labels. PLoS One. 2018;13(8):e0202095. https://doi.org/10. 1371/journal.pone.0202095 eCollection 2018.

22. Lohse GL. Consumer eye movement patterns on yellow pages advertising. J Advert. 1997;26:61-73.

23. Egnell M, Crosetto $P$, d'Almeida T, Kesse-Guyot E, Touvier M, Ruffieux B, et al. Modelling the impact of different front-of-package nutrition labels on mortality from non-communicable chronic disease. Int J Behav Nutr Phys Act. 2019;16(1):56. https://doi.org/10.1186/s12966-019-0817-2.

\section{Publisher's Note}

Springer Nature remains neutral with regard to jurisdictional claims in published maps and institutional affiliations.

Ready to submit your research? Choose BMC and benefit from:

- fast, convenient online submission

- thorough peer review by experienced researchers in your field

- rapid publication on acceptance

- support for research data, including large and complex data types

- gold Open Access which fosters wider collaboration and increased citations

- maximum visibility for your research: over $100 \mathrm{M}$ website views per year

At BMC, research is always in progress.

Learn more biomedcentral.com/submissions 